\title{
Doxorubicin-Induced Cardiotoxicity: From Bioenergetic Failure and Cell Death to Cardiomyopathy
}

\author{
Filipa S. Carvalho, ${ }^{1,2}$ Ana Burgeiro, ${ }^{1,3}$ Rita Garcia, ${ }^{3}$ António J. Moreno, ${ }^{2,3}$ \\ Rui A. Carvalho, ${ }^{1,2}$ and Paulo J. Oliveira ${ }^{1 *}$ \\ ${ }^{1} \mathrm{CNC}$ - Center for Neuroscience and Cell Biology, University of Coimbra, 3004-517 Coimbra, Portugal \\ ${ }^{2}$ Department of Life Sciences, University of Coimbra, 3004-517 Coimbra, Portugal \\ ${ }^{3}$ IMAR - Institute of Marine Research, University of Coimbra, Portugal \\ Published online 11 March 2013 in Wiley Online Library (wileyonlinelibrary.com). \\ DOI 10.1002/med.21280
}

\begin{abstract}
Doxorubicin (DOX) is an anticancer anthracycline that presents a dose-dependent and cumulative cardiotoxicity as one of the most serious side effects. Several hypotheses have been advanced to explain DOX cardiac side effects, which culminate in the development of life-threatening cardiomyopathy. One of the most studied mechanisms involves the activation of DOX molecule into a more reactive semiquinone by mitochondrial Complex I, resulting in increased oxidative stress. The present review describes and critically discusses what is known about some of the potential mechanisms of DOX-induced cardiotoxicity including mitochondrial oxidative damage and loss of cardiomyocytes. We also discuss alterations of mitochondrial metabolism and the unique characteristics of DOX delayed toxicity, which can also interfere on how the cardiac muscle handles a "second-hit stress." We also present pharmaceutical and nonpharmaceutical approaches that may decrease DOX cardiac alterations in animal models and humans and discuss the limitations of each strategy. (c) 2013 Wiley Periodicals, Inc. Med. Res. Rev., 34, No. 1,
\end{abstract} $106-135,2014$

Key words: doxorubicin; cardiac metabolism; toxicity; mitochondria

\section{INTRODUCTION: DOXORUBICIN AS A CARDIOTOXIC ANTICANCER AGENT}

Doxorubicin (DOX) is an antitumor anthracycline antibiotic, isolated from colonies of Streptomyces peucetius caesius in 1967., 2 DOX is one of the most-used antitumor anthracyclines, being highly active against an extensive variety of neoplastic diseases, even at lower doses. ${ }^{2}$ The first in vivo studies performed with DOX in cancer animal models demonstrated inhibition of neoplastic proliferation and increased animal survival. ${ }^{1}$ DOX efficacy was tested in humans on different types of malignancies, such as leukemias, lymphomas, and solid tumors,

Correspondence to: Paulo J. Oliveira, PhD, Center for Neuroscience and Cell Biology, Largo Marques de Pombal, University of Coimbra, 3004-517 Coimbra, Portugal, E-mail: pauloliv@ci.uc.pt 
including gynecological, urogenital, endocrine, stomach cancer, as well as Ewing and Kaposi's sarcomas. ${ }^{2,3}$ The mechanisms of action of DOX in tumor cells essentially involve interaction with the nucleus, mitochondria, and biological membranes, although some of these targets are also affected in non-target cells as well. The main mechanisms that have been suggested for DOX anticancer effects include: (1) DOX intercalation into DNA, leading to inhibition of protein synthesis and DNA replication; (2) generation of reactive oxygen species (ROS), leading to DNA damage and/or lipid peroxidation; (3) DNA cross-linking, binding, and alkylation; (4) interference with DNA unwinding or DNA strand separation and helicase activity; (5) direct membrane effect with disruption of the bilayer structure; and (6) initiation of DNA damage via inhibition of topoisomerase II. . $^{4}$

During preliminary toxicity tests in patients, several side effects were detected, including nausea, vomiting, and fever. ${ }^{2}$ Furthermore, a significant incidence of cardiovascular side effects namely hypotension, tachycardia, arrhythmias, and ultimately congestive heart failure were also described. ${ }^{6}$ Acute DOX side effects, including pericarditis-myocarditis or arrhythmias, are generally reversible and clinically manageable. ${ }^{7,8}$ However, the mortality of patients that develop congestive heart failure after DOX chronic treatment can be as high as $50 \%,{ }^{9}$ increasing significantly when cumulative doses higher than $500 \mathrm{mg} / \mathrm{m}^{2}{ }^{6}$

The objective of this review is to critically evaluate old and recent knowledge regarding DOX-induced cardiomyopathy, identifying primary molecular targets, which lead to a deterioration of cardiac performance, resulting in decreased resistance to "second-hit stresses" and developing toward cardiomyopathy. We also explore some of the therapeutics aimed at decreasing DOX cardiotoxicity, pointing out defects and virtues of each strategy.

\section{DOX CARDIOTOXICITY_FROM MOLECULAR EVENTS TO CARDIOMYOPATHY}

\section{A. DOX-Induced Cardiac Toxicity-From Acute to Chronic to Delayed}

Acute DOX injury occurs rapidly after a single dose or course of therapy, with clinical manifestations occurring from a few minutes to a week of treatment. ${ }^{10}$ These manifestations may include transient electrophysiological abnormalities, observed in $20-30 \%$ of patients, which comprise nonspecific ST- and T-wave changes, T-wave flattening, decreased QRS voltage and prolongation of QT interval, sinus tachycardia, and supraventricular arrhythmias. ${ }^{6}$ Although rare, pericarditis or myocarditis syndrome and acute left ventricular failure have been observed in some fatal cases. ${ }^{11-13}$ On the other hand, chronic side effects are more serious, irreversible, and involve the development of cardiomyopathy and ultimately congestive heart failure. $^{14,15}$

The prevalence of left ventricular contractile dysfunction in patients with a cumulative DOX dose of approximately $430-600 \mathrm{mg} / \mathrm{m}^{2}$ is about $50-60 \%$, in which a significant incidence of cardiomyopathic episodes is observed. The incidence of heart failure is nearly $2 \%$ with a cumulative dose of $300 \mathrm{mg} / \mathrm{m}^{2}$ but rapidly increases to $20 \%$ at cumulative doses in excess of more than $550 \mathrm{mg} / \mathrm{m}^{2}{ }^{16-20}$

Early-onset, chronic, progressive cardiotoxicity usually occurs within a year of treatment, persisting or progressing even after discontinuation of anthracycline therapy, leading to chronic dilated cardiomyopathy in adult patients and to restrictive cardiomyopathy in pediatric patients. ${ }^{16,21}$ DOX-induced left ventricular dysfunction is generally insidious in onset and progressive in nature with cumulative dosage. ${ }^{18,19}$ If treatment with DOX is continued after the onset of subclinical left ventricular dysfunction, a rapid decline in left ventricular function and heart failure occurs. ${ }^{20}$ On the other hand, late-onset progressive cardiotoxicity results in ventricular dysfunction, heart failure, and arrhythmias years or even decades after chemotherapy 
occurred, suggesting the need for a continuous follow-up of the cardiac status of patients who received anthracyclines. ${ }^{21,22}$

\section{B. Risk Factors}

A number of risk factors contributes to DOX-induced cardiotoxicity, including the total cumulative dose, total dose administered during a day or a course of treatment, rate and schedule of administration, mediastinal radiation, age, gender, concurrent administration of cardiotoxic agents, combined therapy, prior anthracycline chemotherapy, history of preexisting cardiovascular disorders, hypertension, liver disease, and electrolyte imbalances such as hypokalaemia and hypomagnesaemia. ${ }^{13,17,23,24}$ Age seems to be the most significant risk factor since children, adolescents, and elderly patients are the most susceptible to the cardiotoxic effects of DOX chemotherapy. ${ }^{25-27}$ Particularly in children, the reason may be related to specific effects on pluripotent stem cells in postnatal hearts, disturbing their ability to differentiate to functional cardiomyocytes. Similarly to other undifferentiated cells, cardiac stem cells can be more susceptible to DOX and their loss will limit the regenerative capacity of heart. ${ }^{28}$ It is possible that DOX-induced loss of cardiomyocytes together with an early damage to cardiac stem cells in pediatric patients can result in a permanent compromised cardiac function among long-term cancer survivors. Loss of myocytes and impaired cardiac growth results in inadequate left ventricular mass and may result in the development of cardiomyopathy a year or more after cessation of chemotherapy. ${ }^{29}$ Nevertheless, cardiomyocyte atrophy and myofiber disarray may also contribute to cardiac dysfunction observed in DOX-treated juvenile patients or animal models. ${ }^{30}$ Regarding older age groups, aging impacts DOX pharmacokinetics, which is particularly evident in the heart. ${ }^{31,32}$ Age is also highly correlated with drug clearance, which is reduced in the heart tissue of elderly patients and may contribute to DOX-induced cardiotoxicity. ${ }^{33}$ This is critically important as postmortem analysis of patients who were treated with DOX showed high accumulation of this drug in the cardiac tissue versus other muscle tissues. ${ }^{34}$ Age-related DOX cardiotoxicity was also attributed to the decline in regional blood flow with age that may be responsible for the altered DOX concentration-time course in plasma and heart tissue. ${ }^{33}$

Taking into account the diverse risk factors, it is important that each patient treated with DOX undergoes an assessment of baseline cardiac function before chemotherapy, a regular monitoring during treatment and a close lifelong follow-up in an attempt to minimize the risk of development of irreversible cardiotoxicity. ${ }^{19,35}$

DOX-induced cardiotoxicity often results in enlarged hearts, with dilation of all chambers and mural thrombi, commonly observed in both ventricles. ${ }^{36}$ Also, multifocal areas of irregular and interstitial fibrosis and spotted cardiomyocytes with vacuolization were already detected. ${ }^{36}$ Myofibrillar loss and vacuolar degeneration have been two classical ultrastructural features of DOX cardiotoxicity. ${ }^{37}$ Despite the large array of clinical outcomes resulting from DOX toxicity, it has been suggested that a specific, progressive, and subclinical anthracycline injury to the human heart cannot be consistently detected by conventional tests. ${ }^{37}$

\section{The Beginning of the End: DOX-Induced Cardiac Ultrastructural Alterations}

At a cellular and molecular level, DOX cardiotoxicity has been associated with ultrastructural changes in cardiomyocytes, namely cytoplasmic vacuolization involving distention of T-tubules and sarcoplasmic reticulum; myofibrillar disorganization and loss; mitochondrial alterations including swelling ${ }^{35,38-40}$ and cristae disruption ${ }^{41}$; increased number of lysosomes ${ }^{42}$; and clumping of chromatin and nucleoli shrinkage along with segregation of granular and fibrillar components. ${ }^{43}$ DOX disturbs the cellular cytoskeleton and microtubular polymerization, as observed by reduced expression of $\alpha$-actin, myosin light and heavy chains, tropomyosin, 
troponin I, troponin C, and desmin. ${ }^{36,43-45}$ DOX treatment also affects adhesion proteins, such as matrix metalloproteinase MMP-2/MMP-9 gene expression, ${ }^{46}$ resulting in cell detachment. ${ }^{47}$ General mitochondrial and fibrilar disorganization was also detected in human samples. ${ }^{48}$ Most of these effects were replicated in vitro; DOX toxicity on H9c2 cardiomyoblasts includes mitochondrial depolarization and fragmentation and disorganization of the mitochondrial network, structure, as well as cytoskeleton disruption ${ }^{43}$; however, supraclinical concentrations of DOX affect mitochondria more drastically, which is reflected by mitochondrial swelling and loss of mitochondrial cristae in the same model. ${ }^{43}$ DOX toxicity in mitochondria has also been observed in other tissues including brain, ${ }^{49}$ lung, ${ }^{50}$ and liver, ${ }^{51,52}$ although not as extensively as in the heart.

\section{The Beginning of the End: Is DOX-Induced Oxidative Stress in Cardiac Mitochondria the Culprit?}

From a mechanistically point of view, DOX-induced cardiotoxicity has been attributed to a number of causes, including increased oxidative stress, direct inhibition of key transporters involved in ion homeostasis (such as $\mathrm{Na}^{+}-\mathrm{K}^{+}$ATPase and $\mathrm{Ca}^{2+}$ ATPase), which results in alterations in cellular calcium homeostasis, increased cytosolic iron accumulation, mitochondrial failure, inhibition of nucleic acid and protein synthesis, release of vasoactive amines, changes in adrenergic function, lysosomal alterations, and apoptosis. ${ }^{35,49,53}$

The long list of mechanisms that have been proposed to explain the development of DOXinduced cardiomyopathy demonstrates that the cause is probably multifactorial and complex, but most of these alterations may be attributed to free oxygen radicals production, mitochondrial and bioenergetic failure, which may ultimately develop in apoptosis ${ }^{35}$ (Fig. 1).

The heart is particularly susceptible to DOX-induced oxidative damage because of the large density/volume of mitochondria, which are both important sources and targets of ROS (see below), their elevated rate of oxygen consumption, and the lower amount of antioxidant defenses compared with other tissues, such as the liver. ${ }^{41,54,55}$ In fact, cardiomyocytes express low levels of catalase, ${ }^{56}$ while selenium-dependent GSH-peroxidase-1 is readily inactivated after exposure to DOX ${ }^{56}$ which also decreases cytosolic $\mathrm{Cu}-\mathrm{Zn}$ superoxide dismutase. ${ }^{57} \mathrm{~A}$ decrease in the content/activity of antioxidant enzymes may represent a common response to DOX treatment, ${ }^{36}$ at least in a specific time point. But what is the relationship between DOX and oxidative stress?

One major hypothesis for DOX toxicity is based on the generation of oxidative stress through interaction with iron and oxygen. With an univalent redox potential of approximately $-320 \mathrm{mV}, \mathrm{DOX}$ is a favorable substrate for reduction by a number of oxidoreductases within the cell, including NADPH-dependent cytochrome $\mathrm{P} 450$ reductase, ${ }^{58} \mathrm{NADH}$-dehydrogenase of mitochondrial complex I, ${ }^{59,60}$ and assorted soluble oxidoreductases present in the cytoplasm, including xanthine oxidase. ${ }^{61}$ DOX can be reduced by the eNOS reductase domain, enhancing superoxide formation. ${ }^{62}$ Also, it was reported that the $\mathrm{K}_{\mathrm{m}}$ for the reduction of DOX to a semiquinone free radical by eNOS is ten- to 100 -fold lower than the one reported to cytochrome $\mathrm{P} 450$ reductase and NADH dehydrogenase. ${ }^{62}$ As the cardiac tissue has a high number of mitochondria per cell (up to $35 \%$ of the cell volume) when compared with other tissues, it is considered that the main enzyme involved in DOX redox cycling is complex I (NADH:ubiquinone oxidoreductase). ${ }^{18}$ Specifically, DOX is reduced by complex I, forming a highly reactive semiquinone, initiating a redox cycle after reacting with oxygen and releasing ROS in the process (Fig. 2). ${ }^{59}$

DOX also coordinates with free transitional metals, such as iron, to form metal coordination complexes and stimulate production of partially reduced forms of oxygen. ${ }^{63}$ DOX-induced oxygen-free radicals can damage phospholipids in biological membranes, increasing the cell 


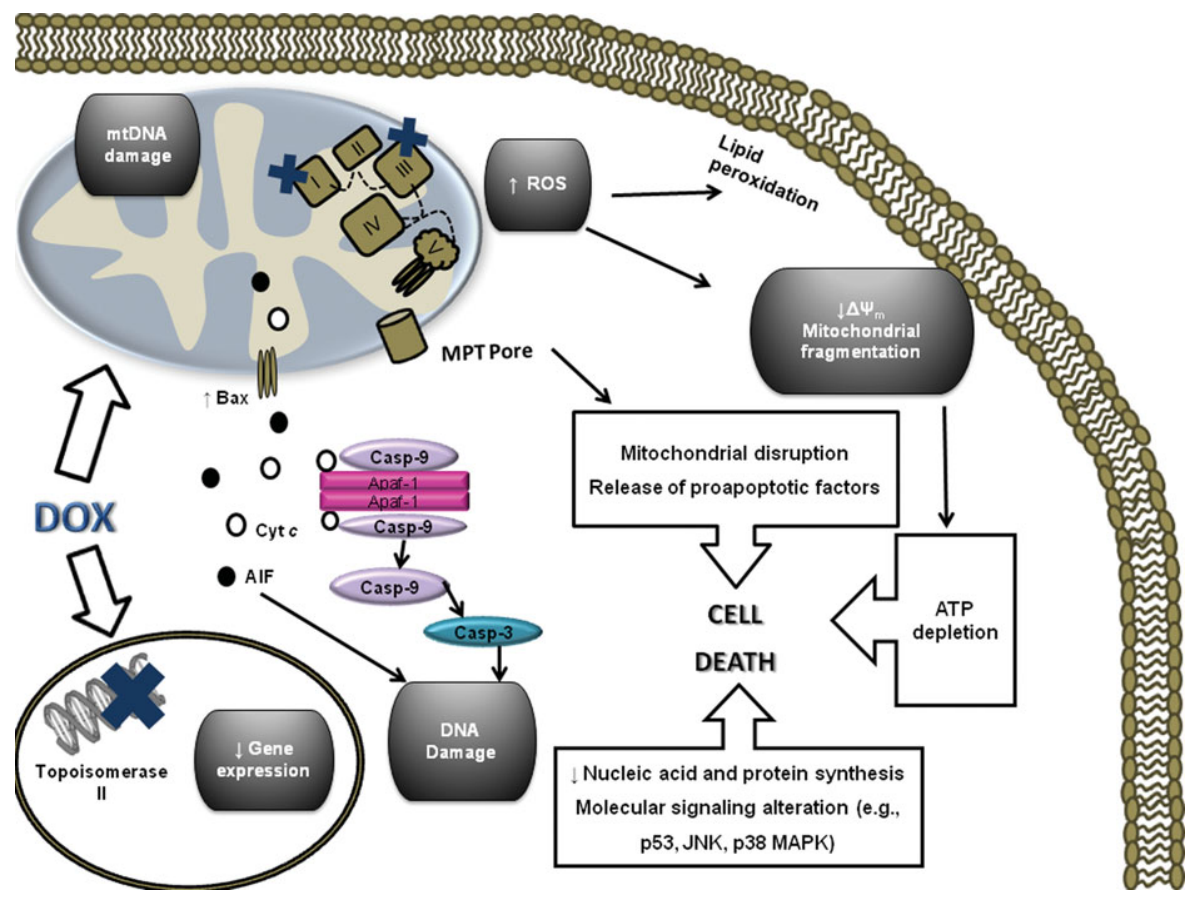

Figure 1. Most consensual model for DOX-induced cardiotoxicity. Data suggest that a large component of DOXinduced cardiotoxicity is mediated by a redox cycle on mitochondrial complex I. Increased ROS generation by DOX redox cycle has several negative consequences, such as mitochondrial transmembrane potential $\left(\Delta \Psi_{\mathrm{m}}\right)$ disruption, MPT pore formation, ATP depletion, and peroxidation of cellular membranes. Marked mitochondrial morphological disturbances induced by DOX include cristae disruption, matrix disorganization, and mitochondrial fragmentation. MPT pore-induced outer membrane rupture due to osmotic swelling or permeabilization of the mitochondrial outer membrane mediated by proapoptotic proteins including BAX can lead to the release of cyt $C$ and AIF. DOX also interferes with topoisomerase II, inhibiting DNA replication and preventing the repair of damage DNA strands. Finally, persistent downregulation of gene expression can be another consequence of DOX toxicity. All of these events may lead to cell death. DOX, doxorubicin; Casp, caspase; $\Delta \Psi_{\mathrm{m}}$, mitochondrial transmembrane potential; ROS, reactive oxygen species; MPT, mitochondrial permeability transition; Cyt $C$, cytochrome c; AIF, apoptosis-inducing factor; JNK, c-Jun N-terminal kinase; MAPK, mitogen-activated protein kinase; ATP, adenosine triphosphate.

membrane permeability and inactivating membrane receptors and other enzymes. ${ }^{64,65}$ DOX also presents a strong affinity for cardiolipin, ${ }^{66,67}$ one of the most abundant phospholipids in the inner mitochondrial membrane (IMM) and which is required for the activity of respiratory chain enzymes such as cytochrome $c$ oxidase and NADH cytochrome $c$ oxidoreductase. ${ }^{68}$ The formation of drug-lipid complexes leads to an inhibition of oxidative phosphorylation because cardiolipin can no longer act as cofactor for mitochondrial enzymes. ${ }^{69}$ Binding of DOX to cardiolipin suggests a strong affinity for mitochondrial membranes. It remains to be determined whether this contributes to a buildup of a DOX gradient across mitochondrial membranes. In other words, it is still unclear the percentage of total DOX which crosses the IMM and gets reduced by complex $\mathrm{I}$ in the matrix side.

Since evidences point out to a preferential interaction of DOX with cardiac mitochondria, it is not surprising that several mitochondrial alterations including stimulation of respiratory state 4 and decrease in respiratory state 3 , as well as a decrease in the respiratory control ratio, have been measured in different models. ${ }^{38,52,70-72}$ DOX-increased ROS generation resulted in the oxidation of lipids, proteins, and signaling molecules. ${ }^{73-75}$ A decrease in mitochondrial membrane potential has also been described..$^{75}$ 


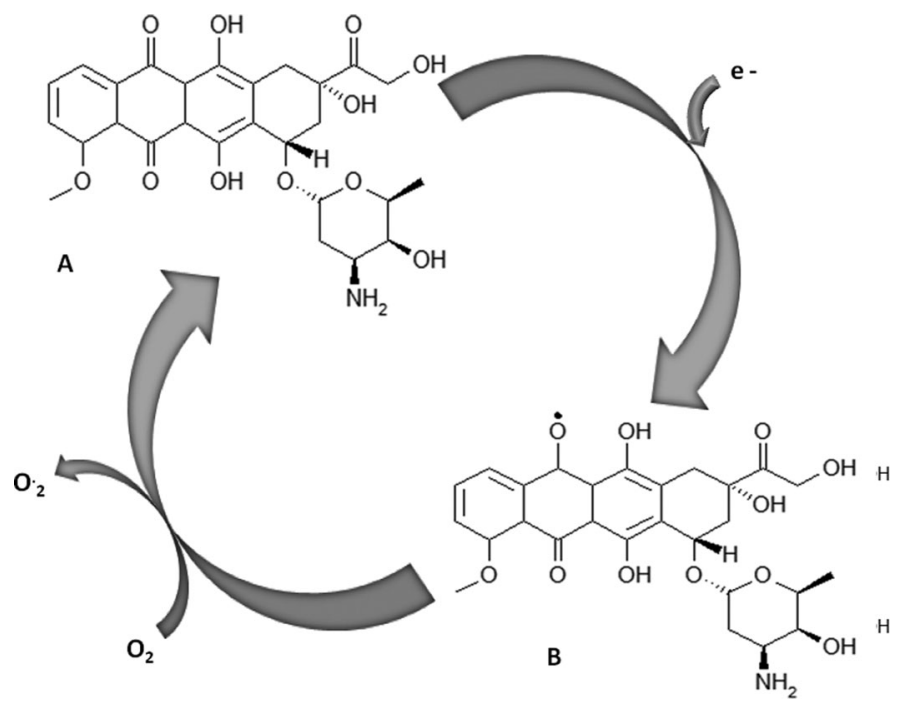

Figure 2. Redox cycling of DOX. Univalent reduction $\left(\mathrm{e}^{-}\right)$of $\mathrm{DOX}(\mathrm{A})$ leads to the formation of a semiquinone radical $(B)$, which can auto-oxidize in the presence of oxygen, generating superoxide anions, reverting to the parent compound.

In several in vitro and in vivo models, one particular aspect of DOX toxicity is a loss of mitochondrial calcium loading capacity. ${ }^{38,51,52,70,71}$ Cardiac mitochondria isolated from DOXtreated rats do not accumulate the same amount of calcium as their control counterparts. It was demonstrated that the loss of calcium loading capacity was due to increased induction of the mitochondrial permeability transition (MPT) pore (Fig. 3) ${ }^{51,76}$ which is a deleterious phenomenon for mitochondria and cells, and which may initiate cell death induction. ${ }^{77}$ Oxidative stress, calcium overload, or irreversible mitochondrial depolarization result in MPT induction, and which results in increased permeability of the IMM, leading to the opening of nonselective protein pores, which allows the passage of smaller molecules below $1.5 \mathrm{kDa}^{78}$

Mitochondrial permeability transition pore opening leads to mitochondrial osmotic swelling and structural damage to mitochondria. The exact molecular nature of MPT is still a matter of debate. Although several authors initially supported the idea that the MPT pore was formed by the voltage-dependent anion channel (VDAC), adenine nucleotide translocase (ANT), and cyclophilin D (Cyp D, also called Cyp F), it has become clear that Cyp D is the only essential component of the MPT pore. ${ }^{79-81}$ Work performed in knockout (KO) animals demonstrated that mitochondria from ANT- and VDAC-KO animals still undergo the MPT..$^{80,82-84}$ Recent ideas suggest that the phosphate carrier $(\mathrm{PiC})$ is instead the better candidate for the MTP pore structural component. ${ }^{80,85-87}$ Several proteins can regulate the MPT, including creatine kinases (CK), hexokinase, Bcl-2 family proteins, and peripheral-type benzodiazepine receptor. ${ }^{88}$ The opening of MPT pore can trigger the release of proapoptotic proteins such as cytochrome $c$ or SMAC/DIABLO due to rupture of the outer mitochondrial membrane or due to the recruitment of proapoptotic proteins. ${ }^{80}$

Increased MPT pore opening in DOX-treated animals can be dependent on the higher basal oxidation of specific thiol residues in mitochondrial proteins. ${ }^{89}$ DOX-induced cardiac MPT pore is prevented by the use of several specific inhibitors such as ATP or Cyclosporin A (CsA).${ }^{90}$ Alterations induced by DOX on the ANT can also lead to altered opening of the MPT pore through an apparent regulatory mode and to decreased oxidative phosphorylation due to its ADP/ATP shuttling activity. ${ }^{70,91,92}$ Inhibition of the ANT in its adenine nucleotide 


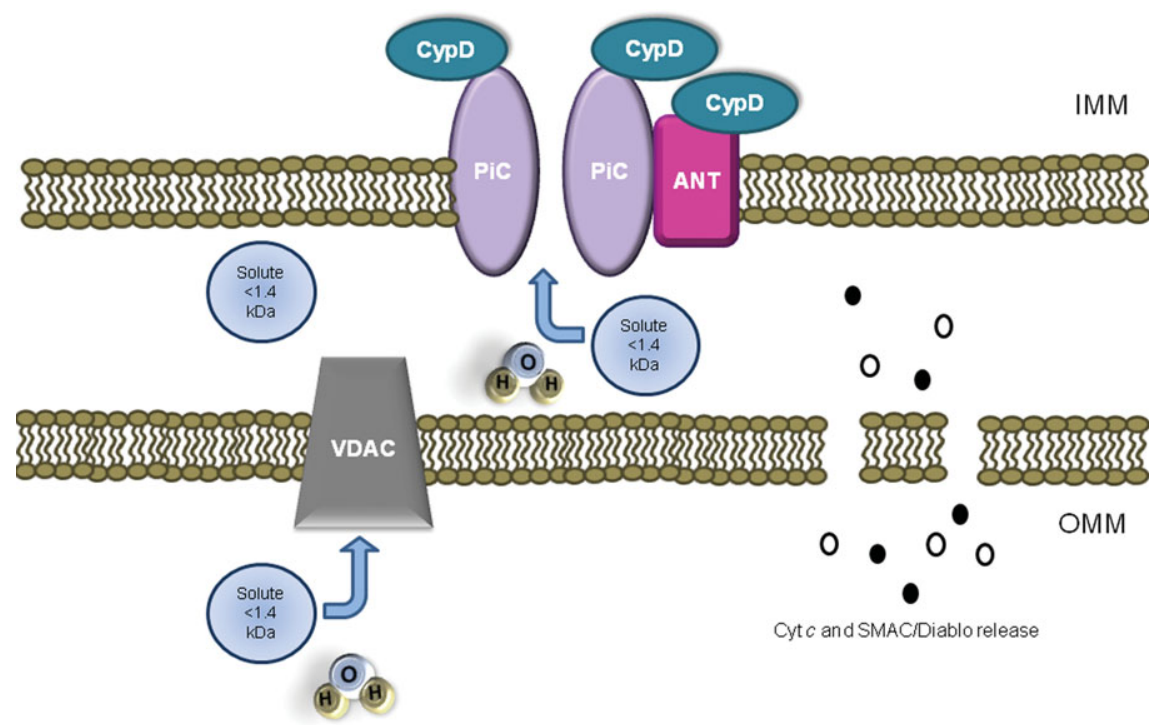

Figure 3. Mitochondrial permeability transition (MPT) pore structure. It was recently proposed that the MPT pore is composed/regulated by the matricial protein cyclophilin $\mathrm{D}(\mathrm{CypD})$ and by the mitochondrial phosphate carrier $(\mathrm{PiC})$, with the adenine nucleotide translocator (ANT) probably having a regulatory role. In addition, the MPT pore can be regulated by other components, such as hexokinase $(\mathrm{HK})$, creatine kinase $(\mathrm{CK})$, and peripheral-type benzodiazepine receptors (PBR). Both antiapoptotic and proapoptotic members of the Bcl-2 family modulate the activity of MPT pore (antiapoptotic members of the Bcl-2 family, including Bcl-2 and Bcl- $\mathrm{X}_{\mathrm{L}}$, inhibit pore opening while proapoptotic Bcl-2 family members, such as Bax, Bak, and Bid, can induce MPT pore opening). Also, MPT pore opening can be inhibited by CypD ligands, such as cyclosporin A (CsA). The opening of MPT pore leads to a collapse of transmembrane mitochondrial transmembrane potential $\left(\Delta \Psi_{\mathrm{m}}\right)$ and favors the release of apoptogenic proteins, such as cytochrome $c$ (Cyt $c$ ) and SMAC/DIABLO (second mitochondria-derived activator of caspases/direct IAP binding protein with low PI).

translocator function can result in an inhibition of respiratory state 3 , which is observed in several in vitro models. ${ }^{93}$ The fact that loss of calcium loading capacity was observed in so many biological models for DOX-induced toxicity led to the cunning idea that this is in fact an early and sensitive marker for DOX-induced cardiotoxicity. ${ }^{38}$ Nevertheless, evidence also exists for a primary mitochondrial membrane depolarization, which precedes a matrix calcium overload and increased ROS production. ${ }^{75}$ Whether the primary event is mitochondrial depolarization or the loss of calcium loading capacity caused by thiol oxidation remains to be confirmed.

Deleterious alterations in cardiac mitochondrial function, including decreased calcium loading capacity and gene expression profile have been demonstrated in rodent models to be irreversible (at least until the studied time point), ${ }^{76,94,95}$ which again supports the notion that DOX toxicity in the myocardium is cumulative and irreversible in nature.

DOX also damages mitochondrial DNA (mtDNA), ${ }^{96}$ by forming adducts with that circular genome and therefore disturbing the process of synthesis of mitochondrial machinery. ${ }^{97-99}$ The oxidation of mtDNA ${ }^{100,101}$ can result in a defective respiratory chain, which will then be unable to respond to high energy demands and produce a higher leakage of electrons to molecular oxygen, increasing ROS production, which then perpetuates the mitochondrial bioenergetic failure. In fact, damage to mtDNA, including loss of mtDNA copies, which closely follows alterations in the respiratory chain, has been described as preceding the accumulation of calcium deposits, suggesting that an early bioenergetic failure may contribute to calcium overload in the matrix. ${ }^{102}$ What is critically important is that mtDNA alterations, including rearrangements, deletions, and decreased copy number, were found in the hearts, but not skeletal muscle, not only from animal models, ${ }^{103}$ but also from deceased patients after DOX treatment. ${ }^{48}$ This 
suggests that mtDNA alterations may accumulate with time, even in the absence of treatment, leading to a defective respiratory chain, which, by its turn, would generate more ROS and contribute to increase mtDNA damage. This appears a great explanation for the persistent and cumulative nature of DOX cardiotoxicity, which suggests a positive feedback loop between mtDNA alterations, respiratory chain deficiencies, both progressing with time, and later matrix calcium accumulation. Once a low bioenergetic threshold is achieved, cardiac mitochondria lose the ability to respond to different stresses by increasing biogenesis, resulting in cardiac failure. In this context, congestive failure would appear decades after treatment due to the progressive nature of mtDNA degeneration. This question should be better confirmed in future studies as well as why other tissues are not so affected.

The above described strongly suggests that DOX-induced oxidative stress can an important factor in the development of cardiac toxicity. If this is true, then a prophylactic measure to stop cardiac deterioration would involve the use of antioxidants. In vitro data indicate that antioxidants are marginally effective to counteract DOX-induced toxicity on cardiomyoblasts ${ }^{104}$; other data confirm that results with antioxidants yield mixed results. ${ }^{105-108}$ One of the first antioxidants tested against DOX cardiotoxicity was vitamin E. ${ }^{55}$ A bolus injection of vitamin E before DOX administration prevented the typical cardiac alterations in mice. ${ }^{109}$ Other studies showed conflicting results regarding the efficiency of vitamin $E$ and further research showed that vitamin $\mathrm{E}$ was cardioprotective only against acute cardiotoxicity resulting from anthracycline chemotherapy but offered no protection against the development of chronic cardiomyopathy. ${ }^{110}$ Berthiaume et al. ${ }^{111}$ showed that vitamin E-succinate prevented cardiac oxidative stress but not mitochondrial alterations. Interestingly, vitamin E-succinate ${ }^{112}$ and vitamin $\mathrm{E}^{113}$ increased the anticancer effects of DOX in tumor cell lines.

Carvedilol, a clinically approved drug that acts as a nonselective $\beta$-adrenergic blocker agent and also blocks $\alpha_{1}$-receptor with vasodilatory properties, has also been described to have potent antioxidant activity. ${ }^{52,108}$ In different models, carvedilol prevented DOX-induced left ventricular dysfunction ${ }^{52,108,114,115}$ and DOX-induced apoptosis of cardiac cells, as well as hydrogen peroxide generation. ${ }^{108}$ Comparing effects of carvedilol with atenolol, another $\beta$ adrenergic blocker agent lacking antioxidant activity, it was concluded that carvedilol protective effects against DOX toxicity resulted predominantly from the antioxidant effect and not from the $\beta$-adrenergic blocker activity, since atenolol did not prevent or inhibit DOX-induced ROS production and cardiac apoptosis. ${ }^{108,114,116}$ Nevertheless, it may be speculated that the cardiac sparing effect of carvedilol, resulting from $\beta$-adrenergic blocking activity, may actually decrease some of the metabolic burden placed on already damaged mitochondria, thus synergizing with the antioxidant effect. Several other studies demonstrated that carvedilol was effective in decreasing cardiac mitochondrial damage induced in a subchronic model for DOX toxicity, including preventing the loss of mitochondrial calcium loading capacity. ${ }^{52,116}$ Interestingly, carvedilol was shown to inhibit a hypothetical cardiac NADH dehydrogenase in the outer leaflet of the IMM, ${ }^{117}$ which was proposed to be another possible mediator of DOX redox cycle in the heart. ${ }^{118}$

However, further studies are necessary to verify if the protective action of carvedilol may be useful not only in the prevention of DOX-induced cardiotoxicity, but also to confirm that carvedilol does not interfere with the DOX antitumor activity. ${ }^{108,114,119,120}$

Despite the positive impact of some antioxidants against DOX cardiotoxicity, the truth is that no one has demonstrated without doubt that macromolecular damage resulting from DOX-generated mitochondrial oxidative stress is the culprit for the cardiomyopathy that results from treatment or if instead mitochondrial oxidative stress only has an important role in the initial acute toxicity observed.

Dexrazoxane is an intracellularly activated chelating agent with structural similarity to EDTA and was found to have cardioprotective effects. ${ }^{121}$ Dexrazoxane prevents functional 
damage of cardiac mitochondria initiated and perpetued by ROS, which leads to a reduction of the incidence of DOX-induced cardiomyopathy in humans and animal models. ${ }^{122-124}$ Despite the advantages of using dexrazoxane against DOX toxicity, this cannot be seen as the proof that oxidative stress is indeed the main culprit of DOX cardiotoxicity. In fact, equally or more potent iron chelators such as desferrioxamine ${ }^{125}$ or deferasirox, ${ }^{126}$ have failed to afford the same degree of protection. This may imply that iron has no role in oxidative stress-mediated DOX toxicity, as previously suggested ${ }^{127}$ or that indeed oxidative stress has a minor role in the entire process of DOX cardiac toxicity. Also, patients treated with dexrazoxane may have a lower tumor response rate. ${ }^{128,129}$ In one clinical trial, patients treated with dexrazoxane presented lower response rates (48\% vs. 63\%) and earlier disease progression compared with patients receiving placebo. ${ }^{130}$

Interestingly, a recent paper confirms that global oxidative stress may not be a major execution step in the development of anthracycline-induced cardiomyopathy; instead, it is proposed that anthracyclines disturb mitochondrial biogenesis in response to energy deficits. ${ }^{131}$ Although this work has been performed with daunorubicin and not with DOX, we may speculate that a similar result may be obtained with the latter. Still, positive results have been obtained in animal models overexpressing antioxidant enzymes including metallothionein, ${ }^{132}$ glutathione peroxidase, ${ }^{133}$ and catalase. ${ }^{134}$ Although the disperse data may appear difficult to conciliate, one possibility is DOX toxicity results in localized oxidative stress, which, despite not causing major macromolecular damage, disturbs the redox equilibrium in different cellular compartments during and after DOX treatment. This localized oxidative stress would interfere with compartmentalized cell signaling and with different redox pairs GSH/GSSG and cysteine/cystine. ${ }^{135,136}$ Differences in the efficacy of iron chelators or antioxidants may be explained by their different intracellular localization/accumulation or even by the fact that antioxidants can disturb an otherwise normal redox balance in specific cell compartments. ${ }^{137}$ This would result in an apparent lack of protective effect against DOX cardiotoxicity. If this hypothesis is confirmed, the development of novel mitochondrial-directed antioxidants/iron chelators could help improving DOX phenotype. One example is MitoQ, which prevented inactivation of mitochondrial complex IV by DOX. ${ }^{138}$

Despite the promising results of multiple antioxidants, a background problem remains: obvious protection against DOX cardiotoxicity observed in animal models rarely translates into a similar protection in humans. Different drug distribution, metabolism and clearance, dissimilar regulation of redox systems at the genetic level or even distinct cardiac metabolism may all be the genesis of interspecies differences.

\section{E. The Beginning of the End: Does DOX-Induced Loss of Cardiac Cells Contribute to Cardiomyopathy?}

Enhanced MPT pore induction resulting from DOX treatment can result in cell death. ${ }^{139,140}$ In fact, a rapidly expanding body of evidence supports the concept that both endothelial cell and cardiomyocyte apoptosis and necrosis are involved in DOX-induced toxicity. ${ }^{141,142}$ The molecular mechanisms underlying DOX-induced cardiomyocyte death comprise the excess generation of $\operatorname{ROS}^{108,139}$ and other ROS-independent mechanisms, including the generation and accumulation of ceramide ${ }^{143}$ or priming of Fas-mediated apoptosis. ${ }^{144}$

DNA damage and signaling pathways involving the tumor suppressor p53 and mitochondria can also be involved in DOX-induced cardiac cell death. ${ }^{104,145}$ DOX not only induces DNA damage and oxidative mitochondrial damage, but also induces nuclear translocation of p53. ${ }^{88}$ Mitochondrial dysfunction in DOX-treated H9c2 cardiomyoblasts was concluded to be secondary to p53 activation. ${ }^{104}$ Upon activation, p53 induces the expression of genes associated with cell arrest, DNA repair, and apoptosis. ${ }^{88}$ Additionally, DOX activation of 
mitochondrial $\mathrm{p} 53^{88}$ can lead to HIF-1 inhibition, ${ }^{146}$ and can promote the decrease of heart mass via p53-dependent inhibition of mTOR signaling. ${ }^{145}$ Moreover, DNA lesions induced by ROS or directly by DOX interaction increase phosphorylation of $\mathrm{p} 53$, upregulate its downstream genes such as Bax ${ }^{104,140}$ and activate JNK and p38 MAPK pathways to induce apoptosis. ${ }^{147}$ Confirming the involvement of the axis p53-Bax, the p53 inhibitor pifithrin- $\alpha$ decreases Bax expression and effectively inhibits DOX-induced apoptosis in H9c2 cells, neonatal rat cardiomyocytes, and mouse hearts. ${ }^{88,148}$

An early event also observed in DOX cardiotoxicity is GATA-4 depletion, which also leads to cardiomyocyte apoptosis. ${ }^{149}$ GATA-4 is a transcriptional factor critical in heart development that regulates the apoptotic pathway by activating the antiapoptotic gene $\mathrm{Bcl}-\mathrm{X}_{\mathrm{L}}$, thus preserving mitochondrial function and integrity. ${ }^{140}$ DOX also inhibits AKT phosphorylation, increasing active GSK $3 \beta$, a negative regulator of GATA-4 in the nucleus. ${ }^{150}$ Also, dephosphorylation of AKT and Bad can activate caspase-3, inducing internucleosomal DNA damage. ${ }^{151}$

Cardiomyocyte apoptosis and consequent cell loss may be a mechanism by which DOX causes a deterioration of cardiac function, as described in different systems. ${ }^{152}$ The evidence supports that DOX activates apoptotic signaling through multiple mechanisms, which apparently include mitochondria as initiators ${ }^{153}$ or at least magnifiers of the apoptotic signaling. Can we inhibit apoptotic signaling to decrease DOX toxicity in the heart? As with antioxidants, the data are confusing and often yields a mixed message. For example, overexpression of the antiapoptotic protein Bcl-xL in neonatal rat cardiomyocytes decreased apoptosis but failed to prevent downregulation of gene expression and ROS generation. ${ }^{154}$ To complicate things further, DOX-induced cardiac cell death may also occur through caspase-independent pathways, ${ }^{155}$ which leaves no space for the effective use of caspase inhibitors. Targeting mitochondrial dysfunction to prevent apoptosis may also prove of limited value since apoptotic signaling originating from other organelles was also found to be important in the context of DOX cardiotoxicity. One of those organelles was shown to be the sarcoplasmic reticulum, leading to activation of caspase $12 .{ }^{156}$ As described above, p53 signaling may be also an important drug target to prevent DOX cardiotoxicity. ${ }^{157}$ Again, this may also prove of limited value as ablation of $\mathrm{p} 53$ via conditional $\mathrm{KO}$ was not enough to prevent DOX-induced fibrosis and cytoskeletal alterations. ${ }^{158}$ Results showing that the p53 inhibitor pifithrin- $\alpha$ may have multiple actions, including decreased expression of different caspase ${ }^{159}$ increases the suspicion that some of the reported protective effects against DOX cardiotoxicity ${ }^{104,148}$ may be, in part, p53 independent.

One important drawback is that the appearance of apoptotic/necrotic cardiomyocytes, as characterized from a morphological point of view, is not a generalized event, at least when detected in postmortem analyses of the cardiac tissue in patients. ${ }^{160}$ It may be also possible that the peak of cardiomyocyte apoptosis may occur still during the treatment, ${ }^{161}$ and that loss of cardiomyocytes or other cardiac cells may be compensated by increased fibrosis, ${ }^{162,163}$ leading to an underestimation of apoptotic cardiomyocyes during post-mortem analysis. Also, the notion that DOX may cause senescence in cardiomyocytes, as opposed to apoptosis, ${ }^{164,165}$ adds another layer of complexity. This new view means that DOX may trigger aging mechanisms in the heart that may, or not, lead to the triggering of apoptotic or even autophagic ${ }^{166,167}$ signaling mechanisms. Another problem is that avoiding apoptotic signaling in the cardiac tissue may also result in exactly the same effect in a cancer cell, which was obviously the first target for DOX. Interestingly, pifithrin- $\alpha$ increased cell death in neoplastic mouse JB6 cells by increasing p53-mediated apoptosis. ${ }^{168}$ This suggests that this compound, regardless of its real selectivity against p53, may contribute to reduce DOX-induced cardiac damage, and at the same time induce death of some tumor types. 


\section{F. Progression of Evil: DOX-Induced Metabolic Remodeling in the Heart}

The progressive degeneration of mitochondrial bioenergetics during DOX treatment may cause cardiac bioenergetic disruption, which may result in cardiac depression. In fact, the ATP or phosphocreatine content of hearts from rats chronically treated with DOX is lower, implying decreased bioenergetic capacity. ${ }^{39}$ Metabolic readjustments are thus necessary to support myocyte vital functions.

Effects on the global cardiac energetic network or on its individual components have been studied in different in vitro and in vivo models for DOX-induced cardiotoxicity. ${ }^{93,169}$ The impact of DOX on global cardiac metabolism is demonstrated by the fact that DOX not only diminishes overall mitochondrial ATP production, but leads to a rather specific early impairment of CK isoenzymes, including mitochondrial CK isoenzymes (MtCK) and AMPK. ${ }^{170,171}$ Compromised MtCK leads to impairment of energy channeling and signaling between mitochondria and the cytosol and interferes with mitochondrial respiration. ${ }^{170,171}$ Inhibition of AMPK, a highly susceptible target of DOX-induced damage in the heart, blocks mitochondrial import and inhibits the $\beta$-oxidation of fatty acids. ${ }^{170}$ Also, impaired AMPK signaling reduces the capacity of the cell to initiate a compensatory increase in glycolytic rate and to stimulate glucose uptake. ${ }^{170,172}$ Glycolytic enzymes have been shown to be associated with sarcolemmal and sarcoplasmic reticular membranes and functionally coupled to ion transport pathways, including calcium channels ${ }^{173}$ or the sodium/proton exchanger. ${ }^{174}$ Alterations in glycolytic fluxes may interfere with ion transport and progressively lead to depression of cardiac excitability.

Also, impairment of carnitine palmitoyl transferase I (CPT I) and/or depletion of its substrate L-carnitine was observed during DOX cardiotoxicity. ${ }^{175,176}$ Since long-chain fatty acid $\beta$-oxidation is inhibited by DOX, ${ }^{177}$ an increase of total cholesterol, triglycerides and LDL cholesterol in the serum can be a consequence, described already in animal models. ${ }^{34,72}$ Both glucose utilization and $\beta$-oxidation of long-chain fatty acids are impaired in DOX-induced cardiomyopathy, ${ }^{36,177,178}$ which taken to the extreme may imply a general breakdown of energy metabolism after DOX treatment.

Interestingly, a link between general oxidative stress and metabolic responses was already proposed. Following 1 hour of DOX treatment, lipid peroxidation increased and caused an adaptive response resulting in an increased glucose uptake that is manifested by an increase in GLUT1 protein, presumably to restore cellular energy, establishing a relationship between DOX-induced lipid peroxidation and acute alterations in glucose transport. ${ }^{178}$ Early responses such as the induction of glycolytic and Krebs cycle genes ${ }^{179}$ may be an adaptation response to a general bioenergetic breakdown, although a metabolic switch from oxidative phosphorylation to glycolysis can only provide a short-term solution (and, as described above, the increase in glycolytic fluxes is limited due to DOX off-target toxicity). An increase of lactate production, a subproduct of glycolysis and a likely signal of decreased mitochondrial function and upregulated glycolysis, was previously described after DOX treatment. ${ }^{177}$ Through nuclear magnetic resonance analysis of intracellular metabolites, myocardial levels of acetate and succinate were increased in DOX-treated animals as compared to controls, which was correlated with nonenzymatic conversion of pyruvate to acetate and of $\alpha$-ketoglutarate to succinate, as mediated by DOX-induced free radicals. ${ }^{180}$ In fact, accumulation of acetate and succinate were proposed as novel biomarkers for DOX cardiotoxicity. ${ }^{180}$ Also, myocardial levels of branched amino acids (BCAAs) valine, leucine, and isoleucine are decreased, meaning that BCAAs can be used as an energy reservoir, resulting from the fact that fatty acid $\beta$-oxidation is inhibited and Krebs cycle is impaired (Fig. 4). ${ }^{180}$

The switch from long-chain fatty acid oxidation to alternative substrates is a common feature of several stressful conditions, in which DOX cardiotoxicity is naturally included and 


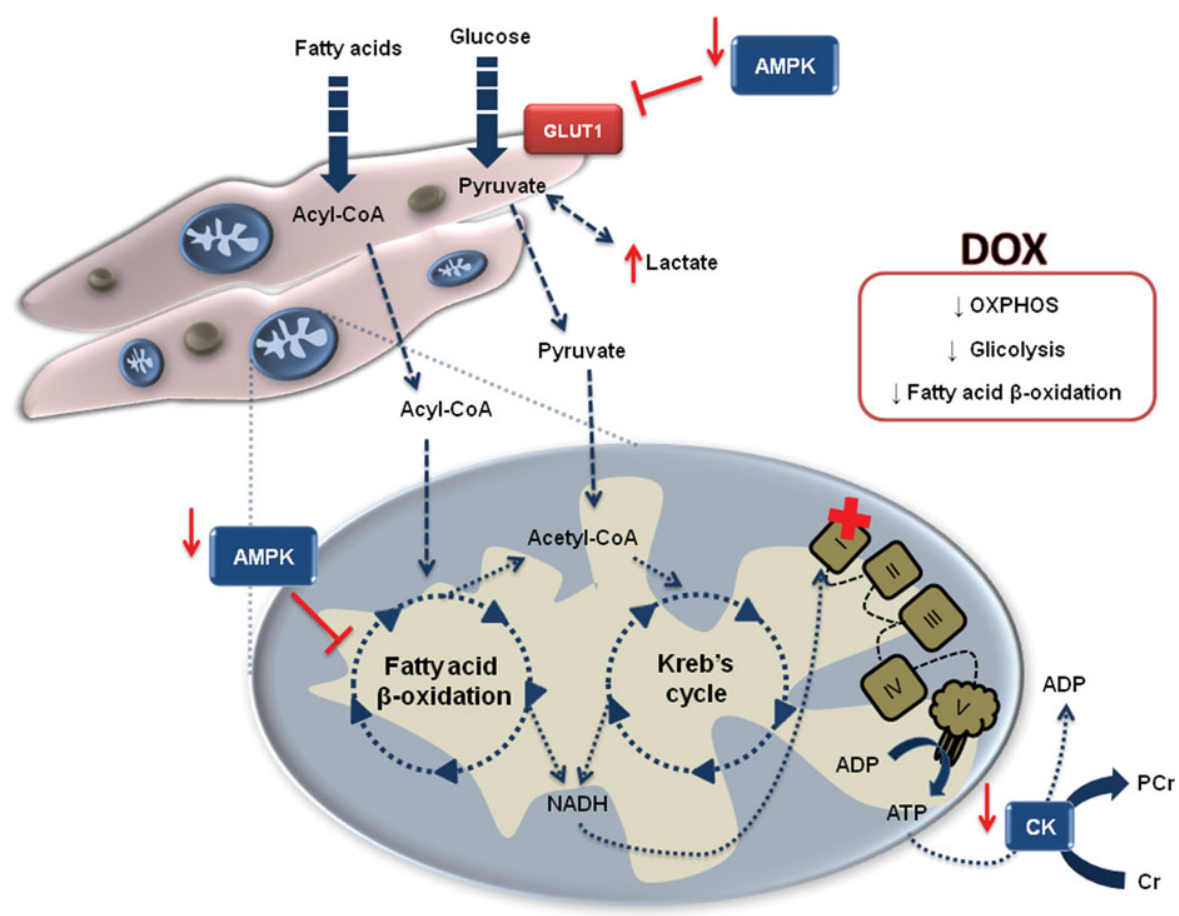

Figure 4. Metabolic alterations described in DOX-induced cardiotoxicity. Cardiac metabolism is altered in different levels by DOX. Besides the disruption of mitochondrial oxidative phosphorylation (OXPHOS), which includes inhibition of Complex I activity, a number of other proteins involved in other metabolic pathways are also affected. Mitochondrial CK isoenzymes (MtCK) are mandatory in the channeling of mitochondrial ATP to creatine-phosphate, used as the source of energy in cardiomyocytes, AMPK activity is also inhibited by DOX, which leads to a decline of fatty acid $\beta$-oxidation. AMPK downregulation negatively affects glucose transporters, blocking the compensatory pathway that stimulates glucose uptake following disrupted OXPHOS. DOX, doxorubicin; AMPK, adenosine monophosphate-activated protein kinase; OXPHOS, oxidative phosphorylation; GLUT1, glucose transporter 1; NADH, nicotinamide adenine dinucleotide; $\mathrm{CK}$, creatine kinase; PCr, phosphocreatine; $\mathrm{Cr}$, creatine; ATP, adenosine triphosphate; ADP, adenosine diphosphate.

may be an important contributor to the metabolic phenotype observed after DOX treatment, resulting in persistent bioenergetic failure. One logical question is to know the extension of the irreversibility of the metabolic injury/remodeling process and how that affects decreased cardiac resistance to future deleterious stresses. However, very few data are available from studies performed in humans, which is clearly a limitation. An important advancement in this field would be a follow-up of global cardiac metabolism in former DOX patients as compared with untreated subjects, not only during rested conditions but also when subjected to cardiac stress (see below).

Studies involving maintenance of regular cardiac metabolism during DOX therapy by using pharmacological strategies are also scarce with some exceptions. L-carnitine, which has an important role in the import of long-chain fatty acids, ${ }^{181}$ has been tested aimed at normalizing metabolism during DOX-induced cardiotoxicity. Results showed some success in decreasing DOX cardiotoxicity in several experimental animal models. ${ }^{182,183}$ Interestingly, L-carnitine supplementation reversed the decreased expression of the organic cation/carnitine transporter in the cardiac muscle ${ }^{184}$ but did not normalize the activities of cardiac CPT-I. ${ }^{185}$ Despite this, hyperlipidemia caused by DOX in rats was decreased by L-carnitine. ${ }^{34}$ The results appear to suggest that L-carnitine may be operating in multiple levels and organs and that restoring longchain fatty acid oxidation may not be the primary mechanism by which L-carnitine operates. 
In fact, the antiapoptotic role of L-carnitine in a in vitro system of DOX toxicity was proposed to originate from direct inhibition of a novel acid sphingomyelinase, which would lead to the generation of ceramide and apoptosis. ${ }^{143}$ This particular aspect may be confusing since it is known that inhibition of mitochondrial fatty acid $\beta$-oxidation at various levels may increase the generation of toxic lipid metabolites, including ceramide, in the cardiomyocyte cytoplasm, leading to cell death. ${ }^{186}$

Dexrazoxane reverted the metabolic consequences of DOX treatment in the heart, such as inhibition of fatty acid $\beta$-oxidation and increased glycolytic rate. In this particular case, a defect in the $\beta$-oxidation mechanism itself and not on fatty acid transport was found after DOX treatment. ${ }^{177}$

Despite the lack of information from humans and from the degree of the reversibility of metabolic alterations, it may be possible that metabolic depression, associated with subclinical mitochondrial limitations, may contribute to decrease the susceptibility of the DOX-treated heart to different types of stresses.

\section{G. "Second-Hit" Stress in the DOX-Treated Hearts}

Since a significant amount of DOX patients are pediatric, one important concern is whether the treated myocardium will have the same behavior when subjected to different types of stress later in life. Evidence from in vitro models, for example, isolated heart mitochondria from DOX-treated rats, suggests that heart mitochondria from this experimental group are more fragile in the presence of calcium and unable to increase respiration facing a demand of ATP, mimicked in vitro by the addition of ADP. ${ }^{89}$ This suggests that DOX toxicity may remain silent and thus undetectable under unstressed situations, but may become visible and a matter of concern when the myocardium is forced to perform stressful work. In fact, the literature is scarce when exploring this subject, that is, there is not a lot of research available on how DOX primes the myocardium to respond differently to different types of stress.

Pregnancy has been considered a potential risk condition for patients that have been previously treated with DOX for childhood cancers. The literature available appears to suggest that pregnancies may have a favorable, complication-free outcome if basal ventricular function is normal before pregnancy. On the other hand, there are risks for the pregnancy if left ventricular function during rest is already deteriorated. ${ }^{187}$ Several peripartum cardiomyopathy and heart failure clinical cases have been described so far, ${ }^{188,189}$ which again shows that patients that were previously treated with DOX in an early age should be followed very closely in the event of a pregnancy. Also, one important point of concern is the fact that offspring from DOX childhood patients may present birth defects or higher cancer incidence. Nevertheless, one available study performed in 405 former childhood cancer survivors, showed no increased rate for any of those end points. ${ }^{190}$

Despite the fact that exercise can prove very beneficial against DOX-induced cardiotoxicity if performed before the treatment ${ }^{191}$ (see below), it can also be a source of metabolic overload for an already stressed cardiac muscle. One interesting and recent paper demonstrated that voluntary exercise in young rats, initiated when DOX treatment was started, was able to prevent the persistence of DOX chronic toxicity. ${ }^{192}$ Data from patients suggest that at least during the initial three decades of life, exercise is not detrimental to the cardiac function in childhood cancer survivors. Black et al. ${ }^{193}$ demonstrated that in most of 56 patients aged 9-28 years, 44 patients of which had been treated with $15-483 \mathrm{mg} / \mathrm{m}^{2}$ DOX, no signs of cardiac alterations were observed during a physical activity protocol. Despite these promising studies, there are voids in the actual knowledge, one being the exercise capacity of older survivors of DOXtreated childhood cancer. The other important aspect, and clearly related to the main topic of the present review, is to question whether the bioenergetic deficit and accompanying metabolic 
remodeling in DOX-treated patients is irreversible and whether these bioenergetic deficits can impact the resistance of the myocardium to "second-hit" stresses, not only including exercise and pregnancy, but also the cardiovascular burden posed by obesity, diabetes, or a lifestyle of increased emotional stress. These topics are still mostly open for investigation.

\section{H. Delayed DOX Toxicity: Can we Stop Something under the Surface?}

As widely described in the previous sections, one particular aspect of DOX toxicity is a delayed component, surfacing years or even decades after treatment. ${ }^{194}$ Despite all the knowledge gathered along the last decades, we are still far from identifying the mechanism(s) behind the delayed cardiac toxicity. It is doubtful that traces of DOX may remain in the cardiac tissue years after cessation of the treatment, despite the fact that DOX may bind to mitochondrial cardiolipin. ${ }^{66,67}$ Proposed mechanisms to explain delayed DOX cardiotoxicity range from progressive impairment of sarcoplasmic reticulum calcium-handling mechanisms, which was observed 13 and 18 weeks after the termination of treatment ${ }^{195}$ to free radical-derived DNA lesions. ${ }^{196}$ One should be aware that DOX-induced oxidative lesions on mtDNA ${ }^{100,101}$ can also contribute to a progressive decay of mitochondrial capacity, which will cease to be subclinical after a certain threshold is crossed. Another possible explanation may involve the selective removal of progenitor cells in young patients, ${ }^{28}$ which will later limit the already restricted regenerative capacity of the heart.

Different therapies have been proposed facing data from animal models. These range from antioxidants such as coenzyme Q10, ${ }^{197}$ calcium antagonists such as flunarizine ${ }^{198}$ or metabolic/antioxidant agents such as trimetazidine. ${ }^{199}$ But again, data in humans are still scarce regarding approaches to prevent DOX delayed toxicity. Also, would it be correct to treat a former cancer patient that received DOX with a myriad of protective compounds, not knowing the impact of this supposedly "protective" therapy in normal cardiac physiology? The fact that DOX cardiotoxicity may remain silent for decades does not motivate the cardiologist or the general practitioner into prescribing drugs for something that may not exist. One possible solution may be physical activity, which has been described to decrease DOX toxicity. The next section will provide positive arguments for the use of regular exercise in improving metabolism and especially mitochondrial capacity in the hearts of former DOX patients. Data exist showing the exercise is effective in counteracting acute and subchronic DOX cardiotoxicity. If demonstrated, a protective role against delayed DOX toxicity will not come as a surprise.

\section{BOOSTING CARDIAC MITOCHONDRIAL CAPACITY AND DEFENSES WITH PHYSICAL ACTIVITY: LIMITING THE DAMAGE}

The beneficial effects of exercise in the cardiac muscle are widely reported, and include upregulation of heart antioxidant systems, ${ }^{200}$ improvement of mitochondrial function, reduction of the formation of lipid peroxidation by-products, ${ }^{201}$ and induction of heat shock proteins (HSPs) overexpression. ${ }^{202}$ Without surprise, exercise affords cross-tolerance against a series of cardiac pathologies and stresses, including diabetes. ${ }^{203}$ It is important to note that exercise can positively modulate some important cardiac defense systems to antagonize the toxic effects caused by DOX treatment. ${ }^{191}$ Exercise can present different types of schedules and intensities, including acute treadmill running, short- or long-term forced endurance training in the form of treadmill running or swimming as well as voluntary physical activity, resulting in different physical responses and mechanical stresses. ${ }^{191,204}$

In fact, a single endurance exercise bout can preserve cardiac function and protect the heart against cardiac dysfunction, oxidative stress, and lipid peroxidation. ${ }^{205-209}$ Wonder 
et al. ${ }^{205}$ reported that an acute exercise bout performed $24 \mathrm{hr}$ before DOX treatment protected against cardiac dysfunction. Also, exercise-induced cardioprotection could partly be explained by a reduction in the generation of ROS; however, the mitochondrial mechanisms responsible for this cardioprotection against DOX effects remained vague. ${ }^{205}$ Ascensão and co-workers ${ }^{51}$ determined the effects of an acute exercise bout on heart mitochondrial function before DOX administration. Exercise prevented most of the deleterious mitochondrial alterations caused by DOX treatment, including the decrease in heart mitochondrial function and increased calcium-induced MPT, besides increasing cardiac mitochondrial SOD activity and preventing apoptotic signaling. Clearly, this study supports that acute exercise protects against cardiac mitochondrial dysfunction. However, due to the high rates of oxygen consumption and ROS production in acute exercise and to the low cardiac muscle ability to neutralize ROS, acute exercise should be recommended only under controlled circumstances, especially for patients with a previous history of heart disease. ${ }^{210,211}$

Endurance training can be defined as the repeated act of exercising to increase aerobic fitness. Long-term endurance training induces many physiological adaptations, which have been described to counteract several pathologies. ${ }^{212,213}$ Regular exercise is known to upregulate cardiac antioxidant systems and to support greater tolerance in the myocardium, with a resulting broad enhancement in its function, both at rest and when subjected to oxidative stress stimuli. ${ }^{211}$ Ascensão et al. ${ }^{41,204}$ demonstrated that endurance exercise, prior to DOX treatment, protected the hearts of rats and mice against DOX cardiotoxicity. Also, training prevented the induction of the MPT pore by decreasing the sensitivity to calcium observed in nontrained DOX-treated rats. ${ }^{41,204}$ Moreover, training inhibited a DOX-induced increase in mitochondrial protein carbonyl groups and lipid peroxidation, ${ }^{214}$ and $\mathrm{Bax}, \mathrm{Bax} / \mathrm{Bcl}-2$ ratio, induction of MPT pore and tissue caspase- 3 activity. ${ }^{41}$ Contributing to the protective phenotype, endurance training increased GSH, mitochondrial HSP-60, whole tissue HSP-70, ${ }^{214}$ and mitochondrial and cytosolic forms of SOD. ${ }^{41,204}$ All of these effects resulting from endurance training were able to protect and improve heart mitochondrial respiratory function from the toxic effects of DOX, probably by improving mitochondrial and cell defense systems and reducing cell oxidative stress. All of these modifications at the cellular and ultrastructural levels are reflected in an improvement of cardiac functional parameters. For instance, endurance training prevented DOX-induced decrease in heart rate, left ventricular developed pressure and $\mathrm{dP} / \mathrm{dtmax} .^{214}$

Regrettably, there is a shortage of basic scientific works demonstrating the impact of the diverse forms of exercise in cardiac metabolism, including fatty acid $\beta$-oxidation and glycolytic rates. The promising results obtained with exercise in the context of DOX cardiotoxicity would warrant such an approach. Nevertheless, a word of caution must be said. One size does not fit all. Patients should be carefully seen by a cardiologist before starting an endurance training protocol and during several time points. Our limited knowledge of the mechanisms that exercise activates to afford cell protection, combined with the unknown involving DOX delayed toxicity, inhibits the use of physical activity to prevent the latter before further studies.

Interestingly, caloric restriction may resemble the positive effects of exercise. Chen et al. ${ }^{215}$ demonstrated that caloric restriction induced by the nonmetabolized mimetic 2-deoxyglucose (2-DG) antagonized DOX-induced rat neonatal cardiomyocyte death. 2-DG decreased intracellular ATP levels by about 20\% but prevented the large deficit of ATP following DOX treatment. Moderate caloric restriction was also demonstrated to be effective by rendering the heart more resistant to DOX toxicity in a rodent model. ${ }^{216}$ The effect was not dependent on differential accumulation of DOX in the heart but on multiple pathways, including activation of JAK/STAT signaling, decreased oxidative stress, or higher ATP/ADP ratio. Fatty acid oxidation in the myocardium was also increased in this model of moderately restricted diet, which may present a positive impact as well. Kawaguchi et al. elegantly demonstrated that increasing cardiac 


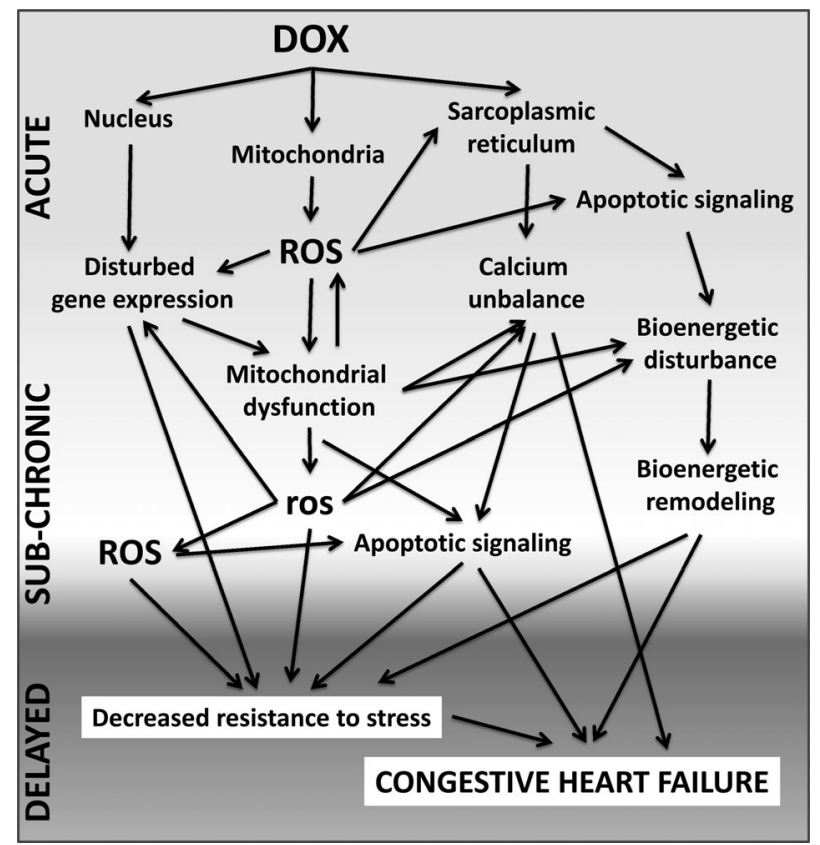

Figure 5. Doxorubicin (DOX): from molecular events to cardiomyopathy. The present figure exemplifies the complexity of the progression of DOX cardiotoxicity from acute events to the still badly understood delayed toxicity, which involves the development of congestive heart failure. The figure extends the schematics shown in the previous figures to a temporal scale. We also propose that DOX causes, not only, macromolecular oxidative damage (ROS), which damages proteins, membranes, and genetic material, but also alters permanently the redox balance in different compartments ("ros," e.g., mitochondria, nucleus, and sarcoplasmic reticulum). Disturbances in the equilibrium of redox pairs GSH/GSSG and cystein/cystine can compromise enzyme activity and several metabolic processes, which can later result in macromolecular oxidative stress. The figure also shows two possible moments when apoptotic signaling may increase. The first occurs after the initial stages of treatment and may affect cardiomyoctes and/or progenitor cells, while a second bout of apoptotic signaling may occur later, when cardiomyocyte metabolic and genetic errors trigger several death pathways. There is not a defined time frame of when the different events occur. What should be clear is that we propose several redundant pathways for cellular damage, which limits the efficacy of protective agents.

autophagy by prior starvation decreases acute DOX cardiotoxicity, suggesting a protective role of cardiac autophagy in removing damaged structures after DOX treatment. ${ }^{217}$ The protective role of caloric restriction may thus be due, at least in part, by increasing autophagic fluxes in the cardiac tissue.

\section{GRAND FINALE AND A LIMITING PROBLEM IN ANIMAL STUDIES}

DOX cardiotoxicity remains a huge challenge in oncology. Since DOX causes a progressive deterioration of mitochondrial metabolism, this can serve as a basis not only for the phenotype observed in DOX-treated animal models and humans but also for the metabolic remodeling that results from DOX treatment and whose consequences for long-term DOX therapy are still largely unknown. The multifactorial nature of DOX effects and the domino effect that each molecular event may trigger (Fig. 5), can explain why protective agents that otherwise are promising on paper, fail to provide the expected protection. It is also important to note that some of the observed cardiovascular effects may also be consequence of DOX toxicity on other organs, including the kidneys, ${ }^{218}$ which although milder than in the heart and 
affecting a lower number of patients, can further complicate the picture and the efficacy of many cytoprotectants.

Also, basic research should be focused on how cell and mitochondrial metabolism are maintained in an altered state and what are the consequences of that for a later life cardiac failure or decreased resistance to "second-hit" stressful events. It also appears logical that mitochondria appear in the first line for protection by pharmacological and nonpharmacological approaches in order to further prevent metabolic remodeling that may prove deleterious in the long term.

One critical problem with several of the animal studies aimed at understanding the mechanisms behind DOX toxicity is the choice of healthy animals in the vast majority of studies. Most studies, including our own, investigate the cardiotoxicity of DOX in animal models devoid of tumors. This extra physiological burden may alter the cardiac effects of DOX, with the advantage of studying the effects of different compounds on cardiac tissue and in modulation of DOX anticancer efficacy. In a model bearing more resemblance to the clinical reality, Todorova et al. ${ }^{219,220}$ observed that oral glutamine administration was able to reduce oxidative damage in the heart of tumor-bearing rats. This study is important for two main reasons. One is the evidence that oral glutamine is able to decrease oxidative damage caused by DOX in the heart but not in the tumor. The second important reason has, of course, to do with the model itself. The authors chose to use an animal model that harbors a tumor. Despite this, this is a step forward in improving the biological model, the truth still is that a rat (or mouse) is different from a human, which justifies that protective agents that work in animal models fail to do so in humans. ${ }^{221}$ Finally, a critical feature of DOX cardiotoxicity is its persistent and delayed nature. With the exception of a few studies, ${ }^{48,71,103,222}$ a need exists for proper models for DOX delayed cardiotoxicity.

In conclusion, much is yet to be done and further research will continuously be conducted in an attempt to validate the essential mechanisms responsible for DOX toxicity and metabolic/mitochondrial alterations involved therein and to develop new therapeutic strategies to prevent premature cardiomyocyte death in cancer patients that benefit from anthracycline treatment. This is an even bigger challenge for childhood cancer survivors.

\section{CONFLICT OF INTERESTS}

The authors declare that they have no conflict of interest. The funding agency had no role in manuscript contents or in the decision to publish the present manuscript. The author's affiliation is as shown on the cover page. The authors have sole responsibility for the writing and content of the paper.

\section{ACKNOWLEDGMENTS}

Work in the authors' laboratory is funded by the Foundation for Science and Technology (FCT, Portugal), research grants PTDC/SAU-OSM/104731/2008, PEstC/SAU/LA0001/2011 and PTDC/EBB-EBI/115810/2009 (FEDER/Compete/National Funds). Filipa Carvalho is the recipient of a PhD fellowship from the FCT (SFRH/BD/64694/2009). Rita Garcia and Ana Burgeiro are recipients of fellowships for Master degree holders and Pos-Docs, respectively, from grant PTDC/SAU-OSM/104731/2008. We are very thankful to Alexandra Holy for editing the manuscript for English content. 


\section{REFERENCES}

1. Bonadonna G, Monfardini S, De Lena M, Fossati-Bellani F. Clinical evaluation of adriamycin, a new antitumour antibiotic. Br Med J 1969;3(5669):503-506.

2. Bonadonna G, Monfardini S, De Lena M, Fossati-Bellani F, Beretta G. Phase I and preliminary phase II evaluation of adriamycin (NSC 123127). Cancer Res 1970;30(10):25722582.

3. Carvalho C, Santos RX, Cardoso S, Correia S, Oliveira PJ, Santos MS, Moreira PI. Doxorubicin: The good, the bad and the ugly effect. Curr Med Chem 2009;16(25):3267-3285.

4. Hortobagyi GN. Anthracyclines in the treatment of cancer. An overview. Drugs 1997;54(Suppl 4):1-7.

5. Aubel-Sadron G, Londos-Gagliardi D. Daunorubicin and doxorubicin, anthracycline antibiotics, a physicochemical and biological review. Biochimie 1984;66(5):333-352.

6. Singal PK, Iliskovic N. Doxorubicin-induced cardiomyopathy. N Engl J Med 1998;339(13):900-905.

7. Villani F, Beretta G, Guindani A. Evaluation of early doxorubicin-induced cardiotoxicity by means of systolic time intervals. Cancer Chemother Pharmacol 1979;3(4):249-251.

8. Bristow MR, Billingham ME, Mason JW, Daniels JR. Clinical spectrum of anthracycline antibiotic cardiotoxicity. Cancer Treat Rep 1978;62(6):873-879.

9. Chatterjee K, Zhang J, Honbo N, Karliner JS. Doxorubicin cardiomyopathy. Cardiology 2010;115(2):155-162.

10. Horenstein MS, Vander Heide RS, L'Ecuyer TJ. Molecular basis of anthracycline-induced cardiotoxicity and its prevention. Mol Genet Metab 2000;71(1-2):436-444.

11. Frishman WH, Sung HM, Yee HC, Liu LL, Keefe D, Einzig AI, Dutcher J. Cardiovascular toxicity with cancer chemotherapy. Curr Prob Cancer 1997;21(6):301-360.

12. Lefrak EA, Pitha J, Rosenheim S, Gottlieb JA. A clinicopathologic analysis of adriamycin cardiotoxicity. Cancer 1973;32(2):302-314.

13. Pai VB, Nahata MC. Cardiotoxicity of chemotherapeutic agents: Incidence, treatment and prevention. Drug Safety 2000;22(4):263-302.

14. Pereira GC, Silva AM, Diogo CV, Carvalho FS, Monteiro P, Oliveira PJ. Drug-induced cardiac mitochondrial toxicity and protection: From doxorubicin to carvedilol. Curr Pharm Des 2011;17(20):2113-2129.

15. Alexander J, Dainiak N, Berger HJ, Goldman L, Johnstone D, Reduto L, Duffy T, Schwartz P, Gottschalk A, Zaret BL. Serial assessment of doxorubicin cardiotoxicity with quantitative radionuclide angiocardiography. New Engl J Med 1979;300(6):278-283.

16. Buzdar AU, Marcus C, Smith TL, Blumenschein GR. Early and delayed clinical cardiotoxicity of doxorubicin. Cancer 1985;55(12):2761-2765.

17. Yeh ET, Tong AT, Lenihan DJ, Yusuf SW, Swafford J, Champion C, Durand JB, Gibbs H, Zafarmand AA, Ewer MS. Cardiovascular complications of cancer therapy: Diagnosis, pathogenesis, and management. Circulation 2004;109(25):3122-3131.

18. Wallace KB. Doxorubicin-induced cardiac mitochondrionopathy. Pharmacol Toxicol 2003;93(3):105-115.

19. Christiansen S, Autschbach R. Doxorubicin in experimental and clinical heart failure. Eur J Cardiothorac Surg 2006;30(4):611-616.

20. Jain D. Cardiotoxicity of doxorubicin and other anthracycline derivatives. J Nucl Cardiol 2000;7(1):53-62.

21. Steinherz LJ, Steinherz PG, Tan CT, Heller G, Murphy ML. Cardiac toxicity 4 to 20 years after completing anthracycline therapy. JAMA 1991;266(12):1672-1677.

22. Pai VB, Nahata MC. Cardiotoxicity of chemotherapeutic agents: Incidence, treatment and prevention. Drug Saf 2000;22(4):263-302. 
23. Lipshultz SE, Lipsitz SR, Mone SM, Goorin AM, Sallan SE, Sanders SP, Orav EJ, Gelber RD, Colan SD. Female sex and drug dose as risk factors for late cardiotoxic effects of doxorubicin therapy for childhood cancer. New Engl J Med 1995;332(26):1738-1743.

24. Danesi R, Fogli S, Gennari A, Conte P, Del Tacca M. Pharmacokinetic-pharmacodynamic relationships of the anthracycline anticancer drugs. Clin Pharmacokinet 2002;41(6):431-444.

25. Lipshultz SE. Exposure to anthracyclines during childhood causes cardiac injury. Semin Oncol 2006;33(3 Suppl 8):S8-S14.

26. Kremer LC, van Dalen EC, Offringa M, Voute PA. Frequency and risk factors of anthracyclineinduced clinical heart failure in children: A systematic review. Ann Oncol 2002;13(4):503-512.

27. Doyle JJ, Neugut AI, Jacobson JS, Grann VR, Hershman DL. Chemotherapy and cardiotoxicity in older breast cancer patients: A population-based study. J Clin Oncol 2005;23(34):8597-8605.

28. De Angelis A, Piegari E, Cappetta D, Marino L, Filippelli A, Berrino L, Ferreira-Martins J, Zheng H, Hosoda T, Rota M, Urbanek K, Kajstura J, Leri A, Rossi F, Anversa P. Anthracycline cardiomyopathy is mediated by depletion of the cardiac stem cell pool and is rescued by restoration of progenitor cell function. Circulation 2010;121(2):276-292.

29. Lipshultz SE, Rifai N, Dalton VM, Levy DE, Silverman LB, Lipsitz SR, Colan SD, Asselin BL, Barr RD, Clavell LA, Hurwitz CA, Moghrabi A, Samson Y, Schorin MA, Gelber RD, Sallan SE. The effect of dexrazoxane on myocardial injury in doxorubicin-treated children with acute lymphoblastic leukemia. N Engl J Med 2004;351(2):145-153.

30. Zhu W, Shou W, Payne RM, Caldwell R, Field LJ. A mouse model for juvenile doxorubicin-induced cardiac dysfunction. Pediatr Res 2008;64(5):488-494.

31. Cusack BJ, Musser B, Gambliel H, Hadjokas NE, Olson RD. Effect of dexrazoxane on doxorubicin pharmacokinetics in young and old rats. Cancer Chemother Pharmacol 2003;51(2):139-146.

32. Robert J, Hoerni B. Age dependence of the early-phase pharmacokinetics of doxorubicin. Cancer Res 1983;43(9):4467-4469.

33. Li J, Gwilt PR. The effect of age on the early disposition of doxorubicin. Cancer Chemother Pharmacol 2003;51(5):395-402.

34. Hong YM, Kim HS, Yoon HR. Serum lipid and fatty acid profiles in adriamycin-treated rats after administration of L-carnitine. Pediatr Res 2002;51(2):249-255.

35. Singal PK, Li T, Kumar D, Danelisen I, Iliskovic N. Adriamycin-induced heart failure: Mechanism and modulation. Mol Cell Biochem 2000;207(1-2):77-86.

36. Takemura G, Fujiwara H. Doxorubicin-induced cardiomyopathy from the cardiotoxic mechanisms to management. Prog Cardiovasc Dis 2007;49(5):330-352.

37. Billingham ME, Mason JW, Bristow MR, Daniels JR. Anthracycline cardiomyopathy monitored by morphologic changes. Cancer Treat Rep 1978;62(6):865-872.

38. Oliveira PJ, Bjork JA, Santos MS, Leino RL, Froberg MK, Moreno AJ, Wallace KB. Carvedilolmediated antioxidant protection against doxorubicin-induced cardiac mitochondrial toxicity. Toxicol Appl Pharmacol 2004;200(2):159-168.

39. Tokarska-Schlattner M, Zaugg M, Zuppinger C, Wallimann T, Schlattner U. New insights into doxorubicin-induced cardiotoxicity: The critical role of cellular energetics. J Mol Cell Cardiol 2006;41(3):389-405.

40. Unverferth DV, Magorien RD, Unverferth BP, Talley RL, Balcerzak SP, Baba N. Human myocardial morphologic and functional changes in the first 24 hours after doxorubicin administration. Cancer Treat Rep 1981;65(11-12):1093-1097.

41. Ascensao A, Magalhaes J, Soares JM, Ferreira R, Neuparth MJ, Marques F, Oliveira PJ, Duarte JA. Moderate endurance training prevents doxorubicin-induced in vivo mitochondriopathy and reduces the development of cardiac apoptosis. Am J Physiol Heart Circ Physiol 2005;289(2):H722-H731.

42. Minotti G, Menna P, Salvatorelli E, Cairo G, Gianni L. Anthracyclines: Molecular advances and pharmacologic developments in antitumor activity and cardiotoxicity. Pharmacol Rev 2004;56(2):185-229. 
43. Sardao VA, Oliveira PJ, Holy J, Oliveira CR, Wallace KB. Morphological alterations induced by doxorubicin on H9c2 myoblasts: Nuclear, mitochondrial, and cytoskeletal targets. Cell Biol Toxicol 2009;25(3):227-243.

44. Ferreira AL, Matsubara LS, Matsubara BB. Anthracycline-induced cardiotoxicity. Cardiovasc Hematol Agents Med Chem 2008;6(4):278-281.

45. Gewirtz DA. A critical evaluation of the mechanisms of action proposed for the antitumor effects of the anthracycline antibiotics adriamycin and daunorubicin. Biochem Pharmacol 1999;57(7):727741.

46. Mukhopadhyay P, Rajesh M, Batkai S, Kashiwaya Y, Hasko G, Liaudet L, Szabo C, Pacher P. Role of superoxide, nitric oxide, and peroxynitrite in doxorubicin-induced cell death in vivo and in vitro. Am J Physiol Heart Circ Physiol 2009;296(5):H1466-H1483.

47. DeAtley SM, Aksenov MY, Aksenova MV, Jordan B, Carney JM, Butterfield DA. Adriamycininduced changes of creatine kinase activity in vivo and in cardiomyocyte culture. Toxicology 1999;134(1):51-62.

48. Lebrecht D, Kokkori A, Ketelsen UP, Setzer B, Walker UA. Tissue-specific mtDNA lesions and radical-associated mitochondrial dysfunction in human hearts exposed to doxorubicin. J Pathol 2005;207(4):436-444.

49. Cardoso S, Santos RX, Carvalho C, Correia S, Pereira GC, Pereira SS, Oliveira PJ, Santos MS, Proenca T, Moreira PI. Doxorubicin increases the susceptibility of brain mitochondria to $\mathrm{Ca}(2+)$-induced permeability transition and oxidative damage. Free Radic Biol Med 2008;45(10): $1395-1402$.

50. Machado NG, Baldeiras I, Pereira GC, Pereira SP, Oliveira PJ. Sub-chronic administration of doxorubicin to Wistar rats results in oxidative stress and unaltered apoptotic signaling in the lung. Chem Biol Interact 2010;188(3):478-486.

51. Ascensao A, Lumini-Oliveira J, Machado NG, Ferreira RM, Goncalves IO, Moreira AC, Marques F, Sardao VA, Oliveira PJ, Magalhaes J. Acute exercise protects against calcium-induced cardiac mitochondrial permeability transition pore opening in doxorubicin-treated rats. Clin Sci (Lond) 2011;120(1):37-49.

52. Santos DL, Moreno AJ, Leino RL, Froberg MK, Wallace KB. Carvedilol protects against doxorubicin-induced mitochondrial cardiomyopathy. Toxicol Appl Pharmacol 2002;185(3):218 227.

53. Outomuro D, Grana DR, Azzato F, Milei J. Adriamycin-induced myocardial toxicity: New solutions for an old problem? Int J Cardiol 2007;117(1):6-15.

54. Kaiserova H, Simunek T, Sterba M, den Hartog GJ, Schroterova L, Popelova O, Gersl V, Kvasnickova E, Bast A. New iron chelators in anthracycline-induced cardiotoxicity. Cardiovasc Toxicol 2007;7(2):145-150.

55. Quiles JL, Huertas JR, Battino M, Mataix J, Ramirez-Tortosa MC. Antioxidant nutrients and adriamycin toxicity. Toxicology 2002;180(1):79-95.

56. Doroshow JH, Locker GY, Myers CE. Enzymatic defenses of the mouse heart against reactive oxygen metabolites: Alterations produced by doxorubicin. J Clin Invest 1980;65(1):128-135.

57. Li T, Danelisen I, Singal PK. Early changes in myocardial antioxidant enzymes in rats treated with adriamycin. Mol Cell Cardiol 2002;232(1-2):19-26.

58. Thornalley PJ, Dodd NJ. Free radical production from normal and adriamycin-treated rat cardiac sarcosomes. Biochem Pharmacol 1985;34(5):669-674.

59. Doroshow JH. Anthracycline antibiotic-stimulated superoxide, hydrogen peroxide, and hydroxyl radical production by NADH dehydrogenase. Cancer Res 1983;43(10):4543-4551.

60. Doroshow JH, Davies KJ. Redox cycling of anthracyclines by cardiac mitochondria. II. Formation of superoxide anion, hydrogen peroxide, and hydroxyl radical. J Biol Chem 1986;261(7): 3068-3074.

61. Doroshow JH. Effect of anthracycline antibiotics on oxygen radical formation in rat heart. Cancer Res 1983;43(2):460-472. 
62. Vasquez-Vivar J, Martasek P, Hogg N, Masters BS, Pritchard KA, Jr., Kalyanaraman B. Endothelial nitric oxide synthase-dependent superoxide generation from adriamycin. Biochemistry 1997;36(38):11293-11297.

63. Demant EJ, Jensen PK. Destruction of phospholipids and respiratory-chain activity in pig-heart submitochondrial particles induced by an adriamycin-iron complex. Eur J Biochem 1983;132(3):551556.

64. Marcillat O, Zhang Y, Davies KJ. Oxidative and non-oxidative mechanisms in the inactivation of cardiac mitochondrial electron transport chain components by doxorubicin. Biochem $\mathbf{J}$ 1989;259(1):181-189.

65. Yoon SB, Kajiyama K, Hino Y, Sugiyama M, Ogura R. Effect of adriamycin on lipid peroxide, glutathione peroxidase and respiratory responses of mitochondria from the heart, liver and kidney. Kurume Med J 1983;30(1):1-4.

66. Parker MA, King V, Howard KP. Nuclear magnetic resonance study of doxorubicin binding to cardiolipin containing magnetically oriented phospholipid bilayers. Biochim Biophys Acta 2001;1514(2):206-216.

67. Goormaghtigh E, Huart P, Praet M, Brasseur R, Ruysschaert JM. Structure of the adriamycincardiolipin complex. Role in mitochondrial toxicity. Biophys Chem 1990;35(2-3):247-257.

68. Claypool SM, Koehler CM. The complexity of cardiolipin in health and disease. Trends Biochem Sci 2012;37(1):32-41.

69. Goormaghtigh E, Huart P, Brasseur R, Ruysschaert JM. Mechanism of inhibition of mitochondrial enzymatic complex I-III by adriamycin derivatives. Biochim Biophys Acta 1986;861(1):83-94.

70. Oliveira PJ, Wallace KB. Depletion of adenine nucleotide translocator protein in heart mitochondria from doxorubicin-treated rats-Relevance for mitochondrial dysfunction. Toxicology 2006;220(23):160-168.

71. Zhou S, Starkov A, Froberg MK, Leino RL, Wallace KB. Cumulative and irreversible cardiac mitochondrial dysfunction induced by doxorubicin. Cancer Res 2001;61(2):771-777.

72. Pereira GC, Pereira SP, Pereira CV, Lumini JA, Magalhaes J, Ascensao A, Santos MS, Moreno AJ, Oliveira PJ. Mitochondrionopathy phenotype in doxorubicin-treated wistar rats depends on treatment protocol and is cardiac-specific. PLoS One 2012;7(6):e38867.

73. Berthiaume JM, Wallace KB. Adriamycin-induced oxidative mitochondrial cardiotoxicity. Cell Biol Toxicol 2007;23(1):15-25.

74. Childs AC, Phaneuf SL, Dirks AJ, Phillips T, Leeuwenburgh C. Doxorubicin treatment in vivo causes cytochrome $\mathrm{C}$ release and cardiomyocyte apoptosis, as well as increased mitochondrial efficiency, superoxide dismutase activity, and Bcl-2:Bax ratio. Cancer Res 2002;62(16):4592-4598.

75. Kuznetsov AV, Margreiter R, Amberger A, Saks V, Grimm M. Changes in mitochondrial redox state, membrane potential and calcium precede mitochondrial dysfunction in doxorubicin-induced cell death. Biochim Biophys Acta 2011;1813(6):1144-1152.

76. Zhou S, Starkov A, Froberg MK, Leino RL, Wallace KB. Cumulative and irreversible cardiac mitochondrial dysfunction induced by doxorubicin. Cancer Res 2001;61(2):771-777.

77. Vaseva AV, Marchenko ND, Ji K, Tsirka SE, Holzmann S, Moll UM. p53 opens the mitochondrial permeability transition pore to trigger necrosis. Cell 2012;149(7):1536-1548.

78. Rasola A, Bernardi P. Mitochondrial permeability transition in $\mathrm{Ca}(2+)$-dependent apoptosis and necrosis. Cell Calcium 2011;50(3):222-233.

79. Nakagawa T, Shimizu S, Watanabe T, Yamaguchi O, Otsu K, Yamagata H, Inohara H, Kubo $\mathrm{T}$, Tsujimoto Y. Cyclophilin D-dependent mitochondrial permeability transition regulates some necrotic but not apoptotic cell death. Nature 2005;434(7033):652-658.

80. Baines CP. The molecular composition of the mitochondrial permeability transition pore. $\mathrm{J}$ Mol Cell Cardiol 2009;46(6):850-857.

81. Javadov S, Karmazyn M, Escobales N. Mitochondrial permeability transition pore opening as a promising therapeutic target in cardiac diseases. J Pharmacol Exp Ther 2009;330(3):670-678. 
82. Kokoszka JE, Waymire KG, Levy SE, Sligh JE, Cai J, Jones DP, MacGregor GR, Wallace DC. The $\mathrm{ADP} / \mathrm{ATP}$ translocator is not essential for the mitochondrial permeability transition pore. Nature 2004;427(6973):461-465.

83. Baines CP, Kaiser RA, Sheiko T, Craigen WJ, Molkentin JD. Voltage-dependent anion channels are dispensable for mitochondrial-dependent cell death. Nat Cell Biol 2007;9(5):550-555.

84. Halestrap AP. What is the mitochondrial permeability transition pore? J Mol Cell Cardiol 2009;46(6):821-831.

85. Leung AW, Varanyuwatana P, Halestrap AP. The mitochondrial phosphate carrier interacts with cyclophilin D and may play a key role in the permeability transition. J Biol Chem 2008;283(39):2631226323.

86. Baines CP. The mitochondrial permeability transition pore and ischemia-reperfusion injury. Basic Res Cardiol 2009;104(2):181-188.

87. Halestrap AP, Pasdois $\mathrm{P}$. The role of the mitochondrial permeability transition pore in heart disease. Biochim Biophys Acta 2009;1787(11):1402-1415.

88. Liu J, Mao W, Ding B, Liang CS. ERKs/p53 signal transduction pathway is involved in doxorubicin-induced apoptosis in H9c2 cells and cardiomyocytes. Am J Physiol Heart Circ Physiol 2008;295(5):H1956-H1965.

89. Oliveira PJ, Santos MS, Wallace KB. Doxorubicin-induced thiol-dependent alteration of cardiac mitochondrial permeability transition and respiration. Biochemistry (Mosc) 2006;71(2):194-199.

90. Broekemeier KM, Dempsey ME, Pfeiffer DR. Cyclosporin A is a potent inhibitor of the inner membrane permeability transition in liver mitochondria. J Biol Chem 1989;264(14):7826-7830.

91. McStay GP, Clarke SJ, Halestrap AP. Role of critical thiol groups on the matrix surface of the adenine nucleotide translocase in the mechanism of the mitochondrial permeability transition pore. Biochem J 2002;367(Pt 2):541-548.

92. Halestrap AP, Woodfield KY, Connern CP. Oxidative stress, thiol reagents, and membrane potential modulate the mitochondrial permeability transition by affecting nucleotide binding to the adenine nucleotide translocase. J Biol Chem 1997;272(6):3346-3354.

93. Tokarska-Schlattner M, Wallimann T, Schlattner U. Alterations in myocardial energy metabolism induced by the anti-cancer drug doxorubicin. C R Biol 2006;329(9):657-668.

94. Berthiaume JM, Wallace KB. Persistent alterations to the gene expression profile of the heart subsequent to chronic doxorubicin treatment. Cardiovasc Toxicol 2007;7(3):178-191.

95. Richard C, Ghibu S, Delemasure-Chalumeau S, Guilland JC, Des Rosiers C, Zeller M, Cottin Y, Rochette L, Vergely C. Oxidative stress and myocardial gene alterations associated with doxorubicininduced cardiotoxicity in rats persist for 2 months after treatment cessation. J Pharmacol Exp Ther 2011;339(3):807-814.

96. Ashley N, Poulton J. Mitochondrial DNA is a direct target of anti-cancer anthracycline drugs. Biochem Biophys Res Commun 2009;378(3):450-455.

97. Adachi K, Fujiura Y, Mayumi F, Nozuhara A, Sugiu Y, Sakanashi T, Hidaka T, Toshima H. A deletion of mitochondrial DNA in murine doxorubicin-induced cardiotoxicity. Biochem Biophys Res Commun 1993;195(2):945-951.

98. Ellis CN, Ellis MB, Blakemore WS. Effect of adriamycin on heart mitochondrial DNA. Biochem J 1987;245(1):309-312.

99. Hixon SC, Ellis CN, Daugherty JP. Heart mitochondrial DNA synthesis: Preferential inhibition by adriamycin. J Mol Cell Cardiol 1981;13(9):855-860.

100. Serrano J, Palmeira CM, Kuehl DW, Wallace KB. Cardioselective and cumulative oxidation of mitochondrial DNA following subchronic doxorubicin administration. Biochim Biophys Acta 1999;1411(1):201-205.

101. Palmeira CM, Serrano J, Kuehl DW, Wallace KB. Preferential oxidation of cardiac mitochondrial DNA following acute intoxication with doxorubicin. Biochim Biophys Acta 1997;1321(2): 101-106. 
102. Lebrecht D, Kirschner J, Geist A, Haberstroh J, Walker UA. Respiratory chain deficiency precedes the disrupted calcium homeostasis in chronic doxorubicin cardiomyopathy. Cardiovasc Pathol 2010;19(5):e167-e174.

103. Lebrecht D, Setzer B, Ketelsen UP, Haberstroh J, Walker UA. Time-dependent and tissue-specific accumulation of mtDNA and respiratory chain defects in chronic doxorubicin cardiomyopathy. Circulation 2003;108(19):2423-2429.

104. Sardao VA, Oliveira PJ, Holy J, Oliveira CR, Wallace KB. Doxorubicin-induced mitochondrial dysfunction is secondary to nuclear p53 activation in $\mathrm{H} 9 \mathrm{c} 2$ cardiomyoblasts. Cancer Chemother Pharmacol 2009;64(4):811-827.

105. Singal PK, Iliskovic N, Li T, Kumar D. Adriamycin cardiomyopathy: Pathophysiology and prevention. FASEB J 1997;11(12):931-936.

106. Van Vleet JF, Ferrans VJ, Weirich WE. Cardiac disease induced by chronic adriamycin administration in dogs and an evaluation of vitamin $\mathrm{E}$ and selenium as cardioprotectants. Am J Pathol 1980;99(1):13-42.

107. Yamanaka S, Tatsumi T, Shiraishi J, Mano A, Keira N, Matoba S, Asayama J, Fushiki S, Fliss H, Nakagawa M. Amlodipine inhibits doxorubicin-induced apoptosis in neonatal rat cardiac myocytes. J Am Coll Cardiol 2003;41(5):870-878.

108. Spallarossa P, Garibaldi S, Altieri P, Fabbi P, Manca V, Nasti S, Rossettin P, Ghigliotti G, Ballestrero A, Patrone F, Barsotti A, Brunelli C. Carvedilol prevents doxorubicin-induced free radical release and apoptosis in cardiomyocytes in vitro. J Mol Cell Cardiol 2004;37(4):837-846.

109. Myers CE, McGuire WP, Liss RH, Ifrim I, Grotzinger K, Young RC. Adriamycin: The role of lipid peroxidation in cardiac toxicity and tumor response. Science 1977;197(4299):165-167.

110. Mimnaugh EG, Siddik ZH, Drew R, Sikic BI, Gram TE. The effects of alpha-tocopherol on the toxicity, disposition, and metabolism of adriamycin in mice. Toxicol Appl Pharmacol 1979;49(1):119126.

111. Berthiaume JM, Oliveira PJ, Fariss MW, Wallace KB. Dietary vitamin E decreases doxorubicininduced oxidative stress without preventing mitochondrial dysfunction. Cardiovasc Toxicol 2005;5(3):257-267.

112. Zhang X, Peng X, Yu W, Hou S, Zhao Y, Zhang Z, Huang X, Wu K. Alpha-tocopheryl succinate enhances doxorubicin-induced apoptosis in human gastric cancer cells via promotion of doxorubicin influx and suppression of doxorubicin efflux. Cancer Lett 2011;307(2):174-181.

113. Liu QY, Tan BK. Dietary fish oil and vitamin E enhance doxorubicin effects in P388 tumor-bearing mice. Lipids 2002;37(6):549-556.

114. Matsui H, Morishima I, Numaguchi Y, Toki Y, Okumura K, Hayakawa T. Protective effects of carvedilol against doxorubicin-induced cardiomyopathy in rats. Life Sci 1999;65(12): $1265-1274$.

115. Machado V, Cabral A, Monteiro P, Goncalves L, Providencia LA. Carvedilol as a protector against the cardiotoxicity induced by anthracyclines (doxorubicin). Rev Port Cardiol 2008;27(10):12771296.

116. Oliveira PJ, Rolo AP, Sardao VA, Monteiro P, Goncalves L, Providencia LA, Palmeira CM, Moreno AJ. Advantages in the use of carvedilol versus propranolol for the protection of cardiac mitochondrial function. Rev Port Cardiol 2004;23(10):1291-1298.

117. Oliveira PJ, Santos DJ, Moreno AJ. Carvedilol inhibits the exogenous NADH dehydrogenase in rat heart mitochondria. Arch Biochem Biophys 2000;374(2):279-285.

118. Nohl H. Demonstration of the existence of an organo-specific NADH dehydrogenase in heart mitochondria. Eur J Biochem 1987;169(3):585-591.

119. Noguchi N, Nishino K, Niki E. Antioxidant action of the antihypertensive drug, carvedilol, against lipid peroxidation. Biochem Pharmacol 2000;59(9):1069-1076.

120. Kalay N, Basar E, Ozdogru I, Er O, Cetinkaya Y, Dogan A, Inanc T, Oguzhan A, Eryol NK, Topsakal R, Ergin A. Protective effects of carvedilol against anthracycline-induced cardiomyopathy. J Am Coll Cardiol 2006;48(11):2258-2262. 
121. Hasinoff BB, Herman EH. Dexrazoxane: How it works in cardiac and tumor cells. Is it a prodrug or is it a drug? Cardiovasc Toxicol 2007;7(2):140-144.

122. Swain SM, Whaley FS, Gerber MC, Weisberg S, York M, Spicer D, Jones SE, Wadler S, Desai A, Vogel C, Speyer J, Mittelman A, Reddy S, Pendergrass K, Velez-Garcia E, Ewer MS, Bianchine JR, Gams RA. Cardioprotection with dexrazoxane for doxorubicin-containing therapy in advanced breast cancer. J Clin Oncol 1997;15(4):1318-1332.

123. Kolaric K, Bradamante V, Cervek J, Cieslinska A, Cisarz-Filipcak E, Denisov LE, Donat D, Drosik K, Gershanovic M, Hudziec P, Jelic S, Jurga L, Kalasiewicz M, Kowgird L, Kozacka M, Lichinitzer M, Machalski M, Mechl Z, Odintsov S, Pawlicki M, Rubach D, Roth A, Stabuc B, Tomczak J, Utracka B, Zborzil J, Rogan J. A phase II trial of cardioprotection with cardioxane (ICRF-187) in patients with advanced breast cancer receiving 5-fluorouracil, doxorubicin and cyclophosphamide. Oncology 1995;52(3):251-255.

124. Speyer JL, Green MD, Kramer E, Rey M, Sanger J, Ward C, Dubin N, Ferrans V, Stecy P, ZeleniuchJacquotte A, Wernz J, Feit F, Slater W, Blum R, Muggia F. Protective effect of the bispiperazinedione ICRF-187 against doxorubicin-induced cardiac toxicity in women with advanced breast cancer. N Engl J Med 1988;319(12):745-752.

125. Voest EE, van Acker SA, van der Vijgh WJ, van Asbeck BS, Bast A. Comparison of different iron chelators as protective agents against acute doxorubicin-induced cardiotoxicity. J Mol Cell Cardiol 1994;26(9):1179-1185.

126. Hasinoff BB, Patel D, Wu X. The oral iron chelator ICL670A (deferasirox) does not protect myocytes against doxorubicin. Free Radic Biol Med 2003;35(11):1469-1479.

127. Kaiserova H, den Hartog GJ, Simunek T, Schroterova L, Kvasnickova E, Bast A. Iron is not involved in oxidative stress-mediated cytotoxicity of doxorubicin and bleomycin. Br J Pharmacol 2006;149(7):920-930.

128. Liu XW, Chen ZG, Chua CC, Ma YS, Youngberg GA, Hamdy R, Chua BHL. Melatonin as an effective protector against doxorubicin-induced cardiotoxicity. Am J Physiol Heart Circ Physiol 2002;283(1):H254-H263.

129. Sehested M, Jensen PB, Sorensen BS, Holm B, Friche E, Demant EJF. Antagonistic effect of the cardioprotector (+)-1,2-bis(3,5-dioxopiperazinyl-1-Yl)propane (Icrf-187) on DNA breaks and cytotoxicity induced by the topoisomerase-Ii directed drugs daunorubicin and etoposide ( $\mathrm{Vp}-16)$. Biochem Pharmacol 1993;46(3):389-393.

130. Swain SM, Whaley FS, Gerber MC, Ewer MS, Bianchine JR, Gams RA. Delayed administration of dexrazoxane provides cardioprotection for patients with advanced breast cancer treated with doxorubicin-containing therapy. J Clin Oncol 1997;15(4):1333-1340.

131. Jirkovsky E, Popelova O, Krivakova-Stankova P, Vavrova A, Hroch M, Haskova P, BrcakovaDolezelova E, Micuda S, Adamcova M, Simunek T, Cervinkova Z, Gersl V, Sterba M. Chronic anthracycline cardiotoxicity: Molecular and functional analysis with focus on Nrf2 and mitochondrial biogenesis pathways. J Pharmacol Exp Ther 2012;343(2):468-478.

132. Kang YJ, Chen Y, Yu A, Voss-McCowan M, Epstein PN. Overexpression of metallothionein in the heart of transgenic mice suppresses doxorubicin cardiotoxicity. J Clin Invest 1997;100(6):1501-1506.

133. Xiong Y, Liu X, Lee CP, Chua BH, Ho YS. Attenuation of doxorubicin-induced contractile and mitochondrial dysfunction in mouse heart by cellular glutathione peroxidase. Free Radic Biol Med 2006;41(1):46-55.

134. Kang YJ, Chen Y, Epstein PN. Suppression of doxorubicin cardiotoxicity by overexpression of catalase in the heart of transgenic mice. J Biol Chem 1996;271(21):12610-12616.

135. Go YM, Jones DP. Cysteine/cystine redox signaling in cardiovascular disease. Free Radic Biol Med 2011;50(4):495-509.

136. Jones DP. Radical-free biology of oxidative stress. Am J Physiol Cell Physiol 2008;295(4):C849C868.

137. Poljsak B, Milisav I. The neglected significance of "antioxidative stress". Oxid Med Cell Longev 2012;2012:480895. 
138. Chandran K, Aggarwal D, Migrino RQ, Joseph J, McAllister D, Konorev EA, Antholine WE, Zielonka J, Srinivasan S, Avadhani NG, Kalyanaraman B. Doxorubicin inactivates myocardial cytochrome c oxidase in rats: Cardioprotection by Mito-Q. Biophys J 2009;96(4): $1388-1398$.

139. Kotamraju S, Konorev EA, Joseph J, Kalyanaraman B. Doxorubicin-induced apoptosis in endothelial cells and cardiomyocytes is ameliorated by nitrone spin traps and ebselen. Role of reactive oxygen and nitrogen species. J Biol Chem 2000;275(43):33585-33592.

140. Zhang YW, Shi J, Li YJ, Wei L. Cardiomyocyte death in doxorubicin-induced cardiotoxicity. Arch Immunol Ther Exp (Warsz) 2009;57(6):435-445.

141. Arola OJ, Saraste A, Pulkki K, Kallajoki M, Parvinen M, Voipio-Pulkki LM. Acute doxorubicin cardiotoxicity involves cardiomyocyte apoptosis. Cancer Res 2000;60(7):1789-1792.

142. Zhang YW, Shi J, Li YJ, Wei L. Cardiomyocyte death in doxorubicin-induced cardiotoxicity. Arch Immunol Ther Exp 2009;57(6):435-445.

143. Andrieu-Abadie N, Jaffrezou JP, Hatem S, Laurent G, Levade T, Mercadier JJ. L-carnitine prevents doxorubicin-induced apoptosis of cardiac myocytes: Role of inhibition of ceramide generation. FASEB J 1999;13(12):1501-1510.

144. Yamaoka M, Yamaguchi S, Suzuki T, Okuyama M, Nitobe J, Nakamura N, Mitsui Y, Tomoike H. Apoptosis in rat cardiac myocytes induced by Fas ligand: Priming for Fas-mediated apoptosis with doxorubicin. J Mol Cell Cardiol 2000;32(6):881-889.

145. Zhu W, Soonpaa MH, Chen H, Shen W, Payne RM, Liechty EA, Caldwell RL, Shou W, Field LJ. Acute doxorubicin cardiotoxicity is associated with p53-induced inhibition of the mammalian target of rapamycin pathway. Circulation 2009;119(1):99-106.

146. Yoshida M, Shiojima I, Ikeda H, Komuro I. Chronic doxorubicin cardiotoxicity is mediated by oxidative DNA damage-ATM-p53-apoptosis pathway and attenuated by pitavastatin through the inhibition of Rac1 activity. J Mol Cell Cardiol 2009;47(5):698-705.

147. Ichijo H, Nishida E, Irie K, ten Dijke P, Saitoh M, Moriguchi T, Takagi M, Matsumoto K, Miyazono K, Gotoh Y. Induction of apoptosis by ASK1, a mammalian MAPKKK that activates SAPK/JNK and p38 signaling pathways. Science 1997;275(5296):90-94.

148. Liu X, Chua CC, Gao J, Chen Z, Landy CL, Hamdy R, Chua BH. Pifithrin-alpha protects against doxorubicin-induced apoptosis and acute cardiotoxicity in mice. Am J Physiol Heart Circ Physiol 2004;286(3):H933-H939.

149. Kim Y, Ma AG, Kitta K, Fitch SN, Ikeda T, Ihara Y, Simon AR, Evans T, Suzuki YJ. Anthracycline-induced suppression of GATA-4 transcription factor: Implication in the regulation of cardiac myocyte apoptosis. Mol Pharmacol 2003;63(2):368-377.

150. Suliman HB, Carraway MS, Ali AS, Reynolds CM, Welty-Wolf KE, Piantadosi CA. The CO/HO system reverses inhibition of mitochondrial biogenesis and prevents murine doxorubicin cardiomyopathy. J Clin Invest 2007;117(12):3730-3741.

151. Fan GC, Zhou X, Wang X, Song G, Qian J, Nicolaou P, Chen G, Ren X, Kranias EG. Heat shock protein 20 interacting with phosphorylated Akt reduces doxorubicin-triggered oxidative stress and cardiotoxicity. Circ Res 2008;103(11):1270-1279.

152. Ueno M, Kakinuma Y, Yuhki K, Murakoshi N, Iemitsu M, Miyauchi T, Yamaguchi I. Doxorubicin induces apoptosis by activation of caspase-3 in cultured cardiomyocytes in vitro and rat cardiac ventricles in vivo. J Pharmacol Sci 2006;101(2):151-158.

153. Green PS, Leeuwenburgh C. Mitochondrial dysfunction is an early indicator of doxorubicin-induced apoptosis. Biochim Biophys Acta 2002;1588(1):94-101.

154. Kunisada K, Tone E, Negoro S, Nakaoka Y, Oshima Y, Osugi T, Funamoto M, Izumi M, Fujio Y, Hirota H, Yamauchi-Takihara K. Bcl-xl reduces doxorubicin-induced myocardial damage but fails to control cardiac gene downregulation. Cardiovasc Res 2002;53(4):936-943.

155. Youn HJ, Kim HS, Jeon MH, Lee JH, Seo YJ, Lee YJ. Induction of caspase-independent apoptosis in H9c2 cardiomyocytes by adriamycin treatment. Mol Cell Biochem 2005;270(1-2): 13-19. 
156. Jang YM, Kendaiah S, Drew B, Phillips T, Selman C, Julian D, Leeuwenburgh C. Doxorubicin treatment in vivo activates caspase-12 mediated cardiac apoptosis in both male and female rats. FEBS Lett 2004;577(3):483-490.

157. Velez JM, Miriyala S, Nithipongvanitch R, Noel T, Plabplueng CD, Oberley T, Jungsuwadee P, Van Remmen H, Vore M, St Clair DK. p53 regulates oxidative stress-mediated retrograde signaling: A novel mechanism for chemotherapy-induced cardiac injury. PLoS One 2011;6(3):e18005.

158. Feridooni T, Hotchkiss A, Remley-Carr S, Saga Y, Pasumarthi KB. Cardiomyocyte specific ablation of p53 is not sufficient to block doxorubicin induced cardiac fibrosis and associated cytoskeletal changes. PLoS One 2011;6(7):e22801.

159. Chua CC, Liu X, Gao J, Hamdy RC, Chua BH. Multiple actions of pifithrin-alpha on doxorubicininduced apoptosis in rat myoblastic H9c2 cells. Am J Physiol Heart Circ Physiol 2006;290(6):H2606$\mathrm{H} 2613$.

160. Kajihara H, Yokozaki H, Yamahara M, Kadomoto Y, Tahara E. Anthracycline induced myocardial damage. An analysis of 16 autopsy cases. Pathol Res Pract 1986;181(4):434-441.

161. Arola OJ, Saraste A, Pulkki K, Kallajoki M, Parvinen M, Voipio-Pulkki LM. Acute doxorubicin cardiotoxicity involves cardiomyocyte apoptosis. Cancer Res 2000;60(7):1789-1792.

162. Bernaba BN, Chan JB, Lai CK, Fishbein MC. Pathology of late-onset anthracycline cardiomyopathy. Cardiovasc Pathol 2010;19(5):308-311.

163. Dazzi H, Kaufmann K, Follath F. Anthracycline-induced acute cardiotoxicity in adults treated for leukaemia. Analysis of the clinico-pathological aspects of documented acute anthracyclineinduced cardiotoxicity in patients treated for acute leukaemia at the University Hospital of Zurich, Switzerland, between 1990 and 1996. Ann Oncol 2001;12(7):963-966.

164. Spallarossa P, Altieri P, Aloi C, Garibaldi S, Barisione C, Ghigliotti G, Fugazza G, Barsotti A, Brunelli C. Doxorubicin induces senescence or apoptosis in rat neonatal cardiomyocytes by regulating the expression levels of the telomere binding factors 1 and 2. Am J Physiol Heart Circ Physiol 2009;297(6):H2169-H2181.

165. Maejima Y, Adachi S, Ito H, Hirao K, Isobe M. Induction of premature senescence in cardiomyocytes by doxorubicin as a novel mechanism of myocardial damage. Aging Cell 2008;7(2):125-136.

166. Dimitrakis P, Romay-Ogando MI, Timolati F, Suter TM, Zuppinger C. Effects of doxorubicin cancer therapy on autophagy and the ubiquitin-proteasome system in long-term cultured adult rat cardiomyocytes. Cell Tissue Res 2012;350(2):361-372.

167. Lu L, Wu W, Yan J, Li X, Yu H, Yu X. Adriamycin-induced autophagic cardiomyocyte death plays a pathogenic role in a rat model of heart failure. Int J Cardiol 2009;134(1):82-90.

168. Kaji A, Zhang Y, Nomura M, Bode AM, Ma WY, She QB, Dong Z. Pifithrin-alpha promotes p53-mediated apoptosis in JB6 cells. Mol Carcinog 2003;37(3):138-148.

169. Eidenschink AB, Schroter G, Muller-Weihrich S, Stern H. Myocardial high-energy phosphate metabolism is altered after treatment with anthracycline in childhood. Cardiol Young 2000;10(6):610-617.

170. Tokarska-Schlattner M, Zaugg M, da Silva R, Lucchinetti E, Schaub MC, Wallimann T, Schlattner $\mathrm{U}$. Acute toxicity of doxorubicin on isolated perfused heart: Response of kinases regulating energy supply. Am J Physiol Heart Circ Physiol 2005;289(1):H37-H47.

171. Tokarska-Schlattner M, Wallimann T, Schlattner U. Multiple interference of anthracyclines with mitochondrial creatine kinases: Preferential damage of the cardiac isoenzyme and its implications for drug cardiotoxicity. Mol Pharmacol 2002;61(3):516-523.

172. Gratia S, Kay L, Potenza L, Seffouh A, Novel-Chate V, Schnebelen C, Sestili P, Schlattner U, Tokarska-Schlattner M. Inhibition of AMPK signalling by doxorubicin: At the crossroads of the cardiac responses to energetic, oxidative, and genotoxic stress. Cardiovasc Res 2012;95(3):290-299.

173. Kockskamper J, Zima AV, Blatter LA. Modulation of sarcoplasmic reticulum Ca2+ release by glycolysis in cat atrial myocytes. J Physiol 2005;564(Pt 3):697-714.

174. Sugiyama S, Satoh H, Nomura N, Terada H, Watanabe H, Hayashi H. The importance of glycolytically-derived ATP for the $\mathrm{Na}^{+} / \mathrm{H}^{+}$exchange activity in guinea pig ventricular myocytes. Mol Cell Biochem 2001;217(1-2):153-161. 
175. Abdel-aleem S, El-Merzabani MM, Sayed-Ahmed M, Taylor DA, Lowe JE. Acute and chronic effects of adriamycin on fatty acid oxidation in isolated cardiac myocytes. $\mathbf{J}$ Mol Cell Cardiol 1997;29(2):789-797.

176. Brady LJ, Brady PS. Hepatic and cardiac carnitine palmitoyltransferase activity. Effects of adriamycin and galactosamine. Biochem Pharmacol 1987;36(20):3419-3423.

177. Carvalho RA, Sousa RP, Cadete VJ, Lopaschuk GD, Palmeira CM, Bjork JA, Wallace KB. Metabolic remodeling associated with subchronic doxorubicin cardiomyopathy. Toxicology 2010;270(2-3):92-98.

178. Hrelia S, Fiorentini D, Maraldi T, Angeloni C, Bordoni A, Biagi PL, Hakim G. Doxorubicin induces early lipid peroxidation associated with changes in glucose transport in cultured cardiomyocytes. Biochim Biophys Acta 2002;1567(1-2):150-156.

179. Tokarska-Schlattner M, Lucchinetti E, Zaugg M, Kay L, Gratia S, Guzun R, Saks V, Schlattner U. Early effects of doxorubicin in perfused heart: Transcriptional profiling reveals inhibition of cellular stress response genes. Am J Physiol Regul Integr Comp Physiol 2010;298(4):R1075-R1088.

180. Andreadou I, Papaefthimiou M, Zira A, Constantinou M, Sigala F, Skaltsounis AL, TsantiliKakoulidou A, Iliodromitis EK, Kremastinos DT, Mikros E. Metabonomic identification of novel biomarkers in doxorubicin cardiotoxicity and protective effect of the natural antioxidant oleuropein. NMR Biomed 2009;22(6):585-592.

181. Reuter SE, Evans AM. Carnitine and acylcarnitines: Pharmacokinetic, pharmacological and clinical aspects. Clin Pharmacokinet 2012;51(9):553-572.

182. Luo X, Reichetzer B, Trines J, Benson LN, Lehotay DC. L-carnitine attenuates doxorubicin-induced lipid peroxidation in rats. Free Radic Biol Med 1999;26(9-10):1158-1165.

183. Mijares A, Lopez JR. L-carnitine prevents increase in diastolic [CA2+] induced by doxorubicin in cardiac cells. Eur J Pharmacol 2001;425(2):117-120.

184. Sayed-Ahmed MM, Al-Shabanah OA, Hafez MM, Aleisa AM, Al-Rejaie SS. Inhibition of gene expression of heart fatty acid binding protein and organic cation/carnitine transporter in doxorubicin cardiomyopathic rat model. Eur J Pharmacol 2010;640(1-3):143-149.

185. Yoon HR, Hong YM, Boriack RL, Bennett MJ. Effect of L-carnitine supplementation on cardiac carnitine palmitoyltransferase activities and plasma carnitine concentrations in adriamycin-treated rats. Pediatr Res 2003;53(5):788-792.

186. Lopaschuk GD, Ussher JR, Folmes CD, Jaswal JS, Stanley WC. Myocardial fatty acid metabolism in health and disease. Physiol Rev 2010;90(1):207-258.

187. Bar J, Davidi O, Goshen Y, Hod M, Yaniv I, Hirsch R. Pregnancy outcome in women treated with doxorubicin for childhood cancer. Am J Obstet Gynecol 2003;189(3):853-857.

188. Davis LE, Brown CE. Peripartum heart failure in a patient treated previously with doxorubicin. Obstet Gynecol 1988;71(3 Pt 2):506-508.

189. Katz A, Goldenberg I, Maoz C, Thaler M, Grossman E, Rosenthal T. Peripartum cardiomyopathy occurring in a patient previously treated with doxorubicin. Am J Med Sci 1997;314(6):399-400.

190. Green DM, Fiorello A, Zevon MA, Hall B, Seigelstein N. Birth defects and childhood cancer in offspring of survivors of childhood cancer. Arch Pediatr Adolesc Med 1997;151(4):379-383.

191. Ascensao A, Oliveira PJ, Magalhaes J. Exercise as a beneficial adjunct therapy during doxorubicin treatment - Role of mitochondria in cardioprotection. Int J Cardiol 2012;156(1):4-10.

192. Hayward R, Lien CY, Jensen BT, Hydock DS, Schneider CM. Exercise training mitigates anthracycline-induced chronic cardiotoxicity in a juvenile rat model. Pediatr Blood Cancer 2011.

193. Black P, Gutjahr P, Stopfkuchen H. Physical performance in long-term survivors of acute leukaemia in childhood. Eur J Pediatr 1998;157(6):464-467.

194. Steinherz L, Steinherz P. Delayed cardiac toxicity from anthracycline therapy. Pediatrician 1991;18(1):49-52.

195. Chugun A, Temma K, Oyamada T, Suzuki N, Kamiya Y, Hara Y, Sasaki T, Kondo H, Akera T. Doxorubicin-induced late cardiotoxicity: Delayed impairment of Ca2+-handling mechanisms in the sarcoplasmic reticulum in the rat. Can J Physiol Pharmacol 2000;78(4):329-338. 
196. Monti E, Prosperi E, Supino R, Bottiroli G. Free radical-dependent DNA lesions are involved in the delayed cardiotoxicity induced by adriamycin in the rat. Anticancer Res 1995;15(1): 193-197.

197. Sugiyama S, Yamada K, Hayakawa M, Ozawa T. Approaches that mitigate doxorubicin-induced delayed adverse effects on mitochondrial function in rat hearts; liposome-encapsulated doxorubicin or combination therapy with antioxidant. Biochem Mol Biol Int 1995;36(5):1001-1007.

198. Villani F, Galimberti M, Monti E, Piccinini F, Poggi P, Lanza E, Rozza A, Favalli L. Effect of flunarizine on the delayed cardiotoxicity of doxorubicin in rats. Pharmacol Res 1991;23(2): 195-202.

199. Perletti G, Monti E, Paracchini L, Piccinini F. Effect of trimetazidine on early and delayed doxorubicin myocardial toxicity. Arch Int Pharmacodyn Ther 1989;302:280-289.

200. Ramires PR, Ji LL. Glutathione supplementation and training increases myocardial resistance to ischemia-reperfusion in vivo. Am J Physiol Heart Circ Physiol 2001;281(2):H679-H688.

201. Venditti P, DiMeo S. Antioxidants, tissue damage, and endurance in trained and untrained young male rats. Arch Biochem Biophys 1996;331(1):63-68.

202. Powers SK, Demirel HA, Vincent HK, Coombes JS, Naito H, Hamilton KL, Shanely RA, Jessup $\mathbf{J}$. Exercise training improves myocardial tolerance to in vivo ischemia-reperfusion in the rat. Am J Physiol 1998;275(5 Pt 2):R1468-R1477.

203. Lumini JA, Magalhaes J, Oliveira PJ, Ascensao A. Beneficial effects of exercise on muscle mitochondrial function in diabetes mellitus. Sports Med 2008;38(9):735-750.

204. Ascensao A, Magalhaes J, Soares J, Ferreira R, Neuparth M, Marques F, Oliveira J, Duarte J. Endurance training attenuates doxorubicin-induced cardiac oxidative damage in mice. Int J Cardiol 2005;100(3):451-460.

205. Wonders KY, Hydock DS, Schneider CM, Hayward R. Acute exercise protects against doxorubicin cardiotoxicity. Integr Cancer Ther 2008;7(3):147-154.

206. Taylor RP, Harris MB, Starnes JW. Acute exercise can improve cardioprotection without increasing heat shock protein content. Am J Physiol 1999;276(3 Pt 2):H1098-H1102.

207. Taylor RP, Olsen ME, Starnes JW. Improved postischemic function following acute exercise is not mediated by nitric oxide synthase in the rat heart. Am J Physiol Heart Circ Physiol 2007;292(1):H601-H607.

208. Starnes JW, Taylor RP, Park Y. Exercise improves postischemic function in aging hearts. Am J Physiol Heart Circ Physiol 2003;285(1):H347-H351.

209. Brown DA, Lynch JM, Armstrong CJ, Caruso NM, Ehlers LB, Johnson MS, Moore RL. Susceptibility of the heart to ischaemia-reperfusion injury and exercise-induced cardioprotection are sex-dependent in the rat. J Physiol 2005;564(Pt 2):619-630.

210. Swain DP, Franklin BA. Is there a threshold intensity for aerobic training in cardiac patients? Med Sci Sports Exerc 2002;34(7):1071-1075.

211. Ascensao A, Magalhaes J, Soares J, Oliveira J, Duarte JA. Exercise and cardiac oxidative stress. Rev Port Cardiol 2003;22(5):651-678.

212. Pearson TA, Blair SN, Daniels SR, Eckel RH, Fair JM, Fortmann SP, Franklin BA, Goldstein LB, Greenland P, Grundy SM, Hong Y, Miller NH, Lauer RM, Ockene IS, Sacco RL, Sallis JF, Jr., Smith SC, Jr., Stone NJ, Taubert KA. AHA Guidelines for Primary Prevention of Cardiovascular Disease and Stroke: 2002 Update: Consensus Panel Guide to Comprehensive Risk Reduction for Adult Patients Without Coronary or Other Atherosclerotic Vascular Diseases. American Heart Association Science Advisory and Coordinating Committee. Circulation 2002;106(3):388-391.

213. Thompson PD, Buchner D, Pina IL, Balady GJ, Williams MA, Marcus BH, Berra K, Blair SN, Costa F, Franklin B, Fletcher GF, Gordon NF, Pate RR, Rodriguez BL, Yancey AK, Wenger NK, American Heart Association Council on Clinical Cardiology Subcommittee on Exercise R, Prevention, American Heart Association Council on Nutrition PA, Metabolism Subcommittee on Physical A. Exercise and physical activity in the prevention and treatment of atherosclerotic cardiovascular disease: A statement from the Council on Clinical Cardiology (Subcommittee on 
Exercise, Rehabilitation, and Prevention) and the Council on Nutrition, Physical Activity, and Metabolism (Subcommittee on Physical Activity). Circulation 2003;107(24):3109-3116.

214. Chicco AJ, Schneider CM, Hayward R. Exercise training attenuates acute doxorubicin-induced cardiac dysfunction. J Cardiovasc Pharmacol 2006;47(2):182-189.

215. Chen K, Xu X, Kobayashi S, Timm D, Jepperson T, Liang Q. Caloric restriction mimetic 2deoxyglucose antagonizes doxorubicin-induced cardiomyocyte death by multiple mechanisms. $\mathbf{J}$ Biol Chem 2011;286(25):21993-22006.

216. Mitra MS, Donthamsetty S, White B, Latendresse JR, Mehendale HM. Mechanism of protection of moderately diet restricted rats against doxorubicin-induced acute cardiotoxicity. Toxicol Appl Pharmacol 2007;225(1):90-101.

217. Kawaguchi T, Takemura G, Kanamori H, Takeyama T, Watanabe T, Morishita K, Ogino A, Tsujimoto A, Goto K, Maruyama R, Kawasaki M, Mikami A, Fujiwara T, Fujiwara H, Minatoguchi S. Prior starvation mitigates acute doxorubicin cardiotoxicity through restoration of autophagy in affected cardiomyocytes. Cardiovasc Res 2012;96(3):456-465.

218. Bardi E, Bobok I, V Oláh A, Kappelmayer J, Kiss C. Anthracycline antibiotics induce acute renal tubular toxicity in children with cancer. Pathol Oncol Res 2007;13(3):249-253.

219. Todorova VK, Kaufmann Y, Hennings L, Klimberg VS. Oral glutamine protects against acute doxorubicin-induced cardiotoxicity of tumor-bearing rats. J Nutr 2010;140(1):44-48.

220. Todorova VK, Kaufmann Y, Hennings LJ, Klimberg VS. Glutamine regulation of doxorubicin accumulation in hearts versus tumors in experimental rats. Cancer Chemother Pharmacol 2010;66(2):315-323.

221. Dresdale AR, Barr LH, Bonow RO, Mathisen DJ, Myers CE, Schwartz DE, d'Angelo T, Rosenberg SA. Prospective randomized study of the role of $\mathrm{N}$-acetyl cysteine in reversing doxorubicin-induced cardiomyopathy. Am J Clin Oncol 1982;5(6):657-663.

222. Lebrecht D, Kirschner J, Geist A, Haberstroh J, Walker Ua. Respiratory chain deficiency precedes the disrupted calcium homeostasis in chronic doxorubicin cardiomyopathy. Cardiovasc Pathol 2010;19(5):167-174.

Filipa S. Carvalho obtained her Master Degree in Molecular and Cellular Biology at the University of Coimbra, Portugal in 2009. Currently, she is a PhD student at the Center for Neuroscience and Cell Biology, University of Coimbra, Portugal, focusing her interest in the toxicology of anthracyclines in the cardiac tissue, namely at the energy metabolism level. She works under the supervision of Drs. Oliveira, Carvalho and Moreno. During her Master Degree studies, Filipa Carvalho evaluated the toxicity of several betulinic acid derivatives in cancer and non-cancer cells.

Dr Ana Burgeiro obtained her PhD degree in Biology, Cellular Biology branch, at the Center for Neuroscience and Cell Biology, University of Coimbra, Portugal in 2011. During her PhD, Dr Burgeiro worked in the anti-neoplastic effect of phytochemicals and synthetic ether-lipids, publishing several papers on the subject. Dr Burgeiro is author or co-author of several peerreviewed papers including in the European Journal of Pharmacology, Mitochondrion, Anticancer Drugs, Current Drug Targets and Toxicology in Vitro. During her initial Pos-Doc, Dr. Burgeiro also investigated the cardiac metabolic alterations associated with doxorubicin toxicity. She is initiating a second pos-doc investigating metabolic alterations in the adipose tissue during diabetes.

Rita Garcia is a young researcher working under the supervision of Drs. Oliveira, Carvalho and Moreno. She obtained a MSc. degree in the University of Coimbra in 2009, working on antiinflammatory and analgesic activities of lemon grass. Her current research interests regards the activation of autophagic and apoptotic signaling pathways in the cardiac tissue by doxorubicin. 
António J. Moreno is currently an Associate Professor at the Department of Life Sciences, University of Coimbra since 2003, having been Monitor, Teaching Assistant and Assistant Professsor at the same institution. He is currently a researcher at the Institute of Marine Research, University of Coimbra. António Moreno received his PhD in Biochemistry in 1992 at the University of Coimbra, focusing on the effect of insecticides on hepatic mitochondrial bioenergetics. In 1997, António Moreno was a Visiting Scientist at the Laboratory of Dr. Kendall Wallace, a mitochondrial toxicologist, at the the Department of Biochemistry and Molecular Biology (School of Medicine), University of Minnesota-Duluth, USA. Prof. Moreno is author or co-author of more than 100 full length, peer-reviewed publications, of 2 book chapters and about 200 poster or oral communications in scientific meetings, plus being the editor of 2 books. His current h factor rates 28 (Web of Knowledge). His current research interests include the clarification of the mitochondrial role in the cardiotoxicity of Doxorubicin, the study of new synthetic antioxidants on mitochondrial function and the use of mitochondria as effective biosensors in ecotoxicological research.

Dr. Rui A. Carvalho obtained his Ph.D. at the University of Coimbra, Portugal in 1999, investigating intermediary metabolism by ${ }^{13} C N M R$ isotopopmer analysis. During his Ph.D., Dr. Carvalho trained with Drs. Dean Sherry and Craig Malloy, renowned researchers in NMR studies of metabolism, at the University of Texas - Southwestern Medical Center, Dallas, USA. He was appointed Assistant Professor at the University of Coimbra in 1999 and received his tenure in 2005. Dr. Carvalho is author or co-author of about 100 full length, peer-reviewed publications (including PNAS, Hepatology, ACSnano, Metab Engineering, Biochimica Biophysica Acta, Am $J$ Physiology) and more than 200 poster or oral communications in scientific meetings. His current $h$ factor rates 16 (Web of Knowledge)/18 (Google Scholar). Dr. Carvalho has consistent research funding and acts as ad-hoc reviewer in about 25 different publications. His current research aims at developing stable isotope tracer methodologies for monitoring metabolic pathways at multiple levels, from cancer and stem cells to animals and humans.

Paulo J. Oliveira obtained his PhD at the University of Coimbra, Portugal in 2003 investigating mechanisms of drug and pathology-induced mitochondrial dysfunction. During his PhD, Dr. Oliveira trained with Dr. Kendall Wallace, a renowned toxicologist, at the University of Minnesota, Duluth, USA. During a 4 year Post-doc, Dr. Oliveira spent more time at the University of Minnesota-Duluth, where he published several seminal papers on the mechanisms of doxorubicininduced cardiomyopathy. After being hired as a group leader at the Center for Neuroscience and Cell Biology, University of Coimbra, Portugal, Dr. Oliveira continued his studies on how mitochondrial metabolism is chemically disturbed and how possible pharmacological and nonpharmacological strategies can be designed to prevent that. Dr. Oliveira is author or co-author of about 120 full-length, peer-reviewed publications (including in PLOS One, Biochimica Biophysica Acta, Toxicology and Applied Pharmacology, Current Drug Targets and Biochemical Pharmacology) and more than 250 poster or oral communications in scientific meetings. His current $h$ factor rates 20 (Web of Knowledge)/25 (Google Scholar). Dr. Oliveira has extensive funding and acts as ad-hoc reviewer in about 50 different publications including Nature Protocols, Toxicological Sciences, Toxicology and Applied Pharmacology, American Journal of Physiology, or the British Journal of Pharmacology. His current research aims include investigating how doxorubicin interacts with cardiac mitochondria and metabolism to deteriorate cardiac function and induce cardiomyopathy and how novel mitochondrial-targeted agents and physical activity can prevent mitochondrial damage during doxorubicin-induced mitochondrionopathy. 